Aus der Abteilung Kardiologie und Pneumologie

(Prof. Dr. med. G. Hasenfuß)

im Zentrum Innere Medizin

der Medizinischen Fakultät der Universität Göttingen

\title{
Die Bedeutung der natriuretischen Peptide für die Diagnose einer diastolischen oder systolischen \\ Funktionsstörung
}

\author{
INAUGURAL - DISSERTATION \\ zur Erlangung des Doktorgrades \\ der Medizinischen Fakultät \\ der Georg-August-Universität zu Göttingen
}

\author{
vorgelegt von \\ Marc Uhlir \\ aus \\ Kassel
}

Göttingen 2011 
Dekan: Prof. Dr. med. C. Frömmel

I. Berichterstatter: i. V. Priv.-Doz. Dr. med. Wachter

II. Berichterstatter/in: Priv.-Doz. Dr. med Seeliger

III. Berichterstatter/in: Prof. Dr. med. Oppermann

Tag der mündlichen Prüfung: 27. September 2011 


\section{INHALTSVERZEICHNIS}

$1 \quad$ EINLEITUNG $\quad 8$

$1.1 \quad$ Herzinsuffizienz 8

1.1.1 Definition 9

1.1.2 Ursachen der Herzinsuffizienz 10

$\begin{array}{lll}\text { 1.1.3 Symptome und Zeichen der Herzinsuffizienz } & 11\end{array}$

1.1.4 Stadieneinteilung der Herzinsuffizienz 11

$\begin{array}{ll}\text { 1.1.5 Diagnose der Herzinsuffizienz } & 13\end{array}$

$\begin{array}{lll}\text { 1.1.6 Therapie der Herzinsuffizienz } & 13\end{array}$

1.1.6.1 Medikamentöse Therapien der Herzinsuffizienz 14

1.1.7 Komplikationen und Folgen der Herzinsuffizienz 15

1.2. Definition, Prävalenz und Pathophysiologie der diastolischen Dysfunktion 15

$\begin{array}{lll}1.3 & \text { Natriuretische Peptide } & 19\end{array}$

$\begin{array}{lll}\text { 1.3.1 } & \text { Entdeckung } & 19\end{array}$

1.3.2 Freisetzung, physiologische Bedeutung und Metabolismus der $\begin{array}{ll}\text { natriuretischen Peptide } & 19\end{array}$

1.3.3 Natriuretische Peptide und ihre Bedeutung für die kardiovaskuläre $\begin{array}{ll}\text { Diagnostik } & 21\end{array}$

$1.4 \quad$ Arbeitshypothese der vorliegenden Untersuchung 22

2 MATERIAL UND METHODEN 23

$\begin{array}{lll}2.1 & \text { Rekrutierung der Patienten } & 23\end{array}$

$2.2 \quad$ Anamnese 23

$2.3 \quad$ Körperliche Untersuchung 24

$2.4 \quad$ Blutentnahme und Probenverarbeitung 24

$\begin{array}{lll}2.5 & \text { EKG } & 25\end{array}$

2.6 Echokardiographie 26

$\begin{array}{lll}2.7 & \text { Statistische Analyse } & 27\end{array}$

3 ERGEBNISSE 29

3.1 Patientencharakteristika 29

3.2 NT-proANP-Plasmakonzentration bei Patienten mit normaler

linksventrikulärer Funktion $\quad 30$ 
3.3 BNP-Plasmakonzentration bei Patienten mit normaler

linksventrikulärer Funktion

3.4 NT-proBNP-Plasmakonzentration bei Patienten mit normaler

linksventrikulärer Funktion

3.5 Natriuretische Peptide als Prädikator einer linksventrikulären

Funktionsstörung

3.6 Analyse der ROC-Kurven für eine präklinische ventrikuläre Dysfunktion

3.7 Univariate und multivariate Regressionsanalyse für eine präklinische ventrikuläre Dysfunktion

3.8 Optimierte des Screening-Modells bei einer asymptomatischen linksventrikulären Dysfunktion

4 DISKUSSION

4.1 Bedeutung der natriuretischen Peptide für die Diagnose einer ventrikulären Dysfunktion

4.2 Vergleich von NT-proANP, NT-proBNP und BNP für die Entdeckung einer präklinischen linksventrikulären Dysfunktion 50

4.3 Klinische Bedeutung 52

4.4 Einschränkungen bei der Beurteilung der Ergebnisse dieser Untersuchung $\quad 54$

5 ZUSAMMENFASSUNG 56

6 LITERATURVERZEICHNIS 


\section{Tabellen und Abbildungsverzeichnis}

Tabelle 1: $\quad$ Framingham-Kriterien für die klinische Diagnose einer Herzinsuffizienz 11

Tabelle 2: $\quad$ Herzinsuffizienz-Stadien gemäß New York Heart Association 12

Tabelle 3: Klinische Charakteristika der Studienpatienten 29

Tabelle 4.1: $\quad$ ROC-Analysen bei systolischer Dysfunktion 37

Tabelle 4.2: $\quad$ ROC-Analysen bei systolischer oder schwerer diastolischer $\begin{array}{ll}\text { Dysfunktion } & 37\end{array}$

Tabelle 4.3: $\quad$ ROC-Analysen bei schwerer diastolischer Dysfunktion 38

Tabelle 4.4: $\quad$ ROC-Analysen bei allgemeiner diastolischer Dysfunktion 38

Tabelle 5.1: $\quad$ Multivariate Regression bei systolischer Dysfunktion 40

Tabelle 5.2: Multivariate Regression bei systolischer oder schwerer diastolischer Dysfunktion 40

Tabelle 5.3: Multivariate Regression bei schwerer diastolischer Dysfunktion 41

Tabelle 5.4: Multivariate Regression bei allgemeiner diastolischer Dysfunktion 41

Tabelle 6: Screening-Modelle 45

Abbildung 1: NT-proANP-Plasmakonzentration 30

Abbildung 2: BNP-Plasmakonzentration 31

Abbildung 3: NT-proBNP-Plasmakonzentration 32

Abbildung 4: Natriuretische Peptide und systolische Funktion 33

Abbildung 5: Natriuretische Peptide und diastolische Funktion 34

Abbildung 6: Verhältnis von lnNT-proBNP/lnNT-proANP 35

Abbildung 7: ROC-Kurven der natriuretischen Peptide 36

Abbildung 8: ROC-Kurven des Score-Models 43

Abbildung 9: Score-System verglichen mit NT-proBNP 47 
ACC

ACE

AHA

ANP

AS

AUC

A-Welle

BNP

D

DD

DD-

$\mathrm{dP} / \mathrm{dt}$

DT

$\mathrm{E}_{\text {Decel }}$

E-Welle

$\mathrm{E}^{\prime}$

EF

EKG

GFR

IVRT

KHK

KI

LA

LV

LVEDD

LVEDP

NT-proANP

NT-proBNP

NYHA

O.R.

PCWP

Py
American College of Cardiology

Angiotensin Converting Enzym

American Heart Association

Atrial natriuretic Peptid

Aminosäure

Area under the curve

Einstrom durch Vorhofkontraktionen

Brain natriuretic Peptide

Einstrom in den Vorhof während der Diastole

Diastolische Dysfunktion

Keine diastolische Dysfunktion

Druckabfallgeschwindigkeit

Dezelerationszeit

E-Dezelerationszeit

Passiver Einstrom

Mitralanulusgeschwindigkeit

Ejektionsfraktion

Elektrokardiogramm

Glomeruläre Filtrations-Rate

Isovolumetrische Relaxationszeit (die Zeit in der weder Aortenklappe noch Mitralklappe geöffnet sind)

Koronare Herzkrankheit

Konfidenzintervall

Linkes Atrium

Linker Ventrikel

Linksventrikulärer enddiastolischer Durchmesser

Linksventrikulärer enddiastolischer Druck

N-terminales Pro-Atriales Natriuretisches Peptid

N-terminales Pro-Brain Natriuretisches Peptid

New York Heart Association

Odds Ratio

Pulmonalkapillärer Verschlussdruck

Packyears 


$\begin{array}{ll}\text { RAAS } & \text { Renin-Angiotensin-Aldosteron-System } \\ \text { S } & \text { Einstrom in den Vorhof während der Systole } \\ \text { s } & \text { Standardabweichung } \\ \text { SD } & \text { Systolische Dysfunktion } \\ \text { SD- } & \text { keine systolische Dysfunktion } \\ \text { SD+ } & \text { Systolische Dysfunktion vorhanden } \\ \text { Vp } & \text { Flusspropagationgeschwindigkeit } \\ \text { vs. } & \text { versus } \\ \text { WV } & \text { Wahrscheinlichkeitsverhältnis }\end{array}$




\section{$1 \quad$ EINLEITUNG}

\subsection{Herzinsuffizienz}

Die systolische und die diastolische Herzinsuffizienz sind häufige und kostenintensive Erkrankungen, welche eine häufig gestellte Diagnose der hospitalisierten Patienten in den USA und Europa darstellen (Lee et al. 2004).

Die Prävalenz der chronischen Herzinsuffizienz hat in den letzten Jahren weltweit deutlich zugenommen. So liegt sie in der Gesamtbevölkerung bei $0,3-2,4 \%$. Bei den $>65$-Jährigen beträgt der Anteil 3,0-13\% (Baessler et al. 2003).

Die Herzinsuffizienz ist einer der führenden Gründe der Morbidität und der Mortalität. Sie ist eine fortschreitende Erkrankung, welche oft das Resultat von klinischen unscheinbaren Formen der ventrikulären Dysfunktion (Stadium A und B der AHA/ACC-HerzinsuffizienzKlassifikation (Hunt et al. 2001)) ist. Eine frühe Therapie der asymptomatischen Stadien dieser Erkrankung kann eventuell die Prognose verbessern. Neuere Richtlinien haben neuartige Einteilungen der Herzinsuffizienzstadien angeregt, welche nun Patienten mit dem Risiko für eine linksventrikuläre Dysfunktion oder mit präklinischer linksventrikulärer Dysfunktion (Stadium A und B der AHA/ACC-Herzinsuffizienz-Klassifikation) einschließen (Redfield et al. 2003; Bonow et al. 2005).

Ungefähr 50\% der asymptomatischen linksventrikulären systolischen Dysfunktionen bleiben undiagnostiziert und damit auch unbehandelt. Überdies zeigt eine vorherrschende oder isolierte diastolische Herzinsuffizienz eine vergleichbare Morbiditäts- und Mortalitäts-Rate wie die systolische Herzinsuffizienz (Redfield et al. 2003; SOLVD Investigators 1992; Owen 2006).

Neue Strategien sollten einen kosteneffektiven Ansatz zur Identifikation und Behandlung von Patienten mit dem Risiko einer Herzinsuffizienz beinhalten. Diese sollte zusätzlich eine frühe Behandlung von präklinischen Stadien der Herzinsuffizienz (Stadium B) ermöglichen und zugleich eine Verzögerung der Progression zur symptomatischen Herzinsuffizienz (Stadium C und D) fördern. In Anbetracht der großen Anzahl von Patienten mit dem Risiko für oder mit einer asymptomatischen linksventrikulären Dysfunktion (Stadium A und B) wächst das 
Interesse für den Gebrauch der natriuretischen Peptide als diagnostische Marker der sich verändernden linksventrikulären Funktion (Armstrong und Moe 1994; Davis et al. 1994).

Zahlreiche Studien haben gezeigt, dass erhöhte NT-proBNP- und BNP-Plasmawerte bei Patienten mit einer symptomatischen diastolischen oder systolischen Herzinsuffizienz akzeptable Prädikatoren der linksventrikulären Dysfunktion sind. Allerdings beschäftigten sich nur wenige Studien mit der Bedeutung der natriuretischen Peptide für die Diagnosestellung einer asymptomatischen linksventrikulären systolischen Dysfunktion bei Patienten mit dem Risiko für die Entwicklung einer Herzinsuffizienz (Dahlstrom 2004; Groenning et al. 2004; McDonagh et al. 2004).

\subsubsection{Definition}

Bei der Herzinsuffizienz ist das Herz nicht mehr in der Lage, die Gewebe mit genügend Blut und somit genügend Sauerstoff zu versorgen, um den Gewebestoffwechsel in Ruhe oder unter Belastung sicherzustellen. Klinisch liegt dann eine Herzinsuffizienz vor, wenn typische Symptome wie Dyspnoe, Müdigkeit oder Flüssigkeitsretention bestehen, denen ursächlich eine kardiale Funktionsstörung zugrunde liegt (WHO 1995).

Die Herzinsuffizienz kann in ein Vorwärts- („forward failure“) und Rückwärtsversagen („,backward failure“) eingeteilt werden. Bei dem Vorwärtsversagen liegt eine verminderte Auswurfleistung des Herzmuskels zugrunde. Im Rückwärtsversagen kann eine vermehrte Steifigkeit und daraus folgend eine verminderte Füllung des Ventrikels beobachtet werden (Erdmann 2003).

Eine weitere Einteilung unterscheidet zwischen einer akuten und einer chronischen Form der Herzinsuffizienz. Hierbei wird bei der akuten Form sowohl das de-novo-Auftreten als auch die akute Dekompensation des chronischen Zustands gezählt. Charakterisiert wird diese Dekompensation durch eine Lungenstauung einschließlich des Lungenödems bis zum kardiogenen Schock. Die chronische Herzinsuffizienz wird definiert als Zustand, in dem neben den Symptomen der Herzinsuffizienz auch der objektive Nachweis einer kardialen Dysfunktion durch die Echokardiographie nachweisbar ist (Swedberg et al. 2005). 


\subsubsection{Ursachen der Herzinsuffizienz}

In den westlichen Ländern ist die koronare Herzerkrankung (KHK) die häufigste Ursache einer Herzinsuffizienz (54-70\%) (Cleland et al. 2003).

Bei 80-90\% der herzinsuffizienten Patienten beruhen die klinischen Symptome auf einer ventrikulären Dysfunktion, wobei in etwa 60\% der Fälle eine systolische Funktionsstörung mit einer Ejektionsfraktion (EF) $\leq 40 \%$ vorliegt (Senni und Redfield 2001).

Der akute Myokardinfarkt ist die häufigste Ursache für eine akute Herzinsuffizienz (Wollert und Drexler 1998).

Nach einer initialen myokardialen Schädigung, zum Beispiel durch Herzinfarkt oder Drucküberlastung wie bei der Aortenstenose oder bei einer Myokarditis, kommt es über eine lokale und systemische neuroendokrine Aktivierung zu einem ventrikulären Remodeling und einer weiteren myokardialen Zellschädigung (Cohn et al. 2000).

Bei Patienten mit klinischen Herzinsuffizienzzeichen trotz überwiegend erhaltener systolischer Pumpfunktion spricht man von einer diastolischen Herzinsuffizienz. Diese ist gekennzeichnet durch eine verminderte diastolische Dehnbarkeit (Compliance) sowie verminderte Relaxationsfähigkeit des linken Ventrikels (Gandhi et al. 2001). 


\subsubsection{Symptome und Zeichen der Herzinsuffizienz}

Für die Diagnosestellung einer Herzinsuffizienz müssen definierte klinische Symptome vorliegen und eine kardiale Dysfunktion objektiviert werden. Entsprechend den FraminghamKritierien für die klinische Diagnose einer Herzinsuffizienz sind typische Symptome in der nachfolgenden Tabelle aufgelistet.

\begin{tabular}{|l|l|}
\hline \multicolumn{1}{|c|}{ Kriterien 1. Ordnung } & \multicolumn{1}{c|}{ Kriterien 2. Ordnung } \\
\hline - Paroxymale nächtliche Dyspnoe oder & - Unterschenkelödem \\
Orthopnoe & - Nächtlicher Husten \\
- Halsvenenstauung & - Belastungsdyspnoe \\
- Pulmonale Rasselgeräusche & - Hepatomegalie \\
- Kardiomegalie & - Pleuraergüsse \\
- Akutes Lungenödem & - Tachykardie (Herzfrequenz $>120 /$ min) \\
-3. Herzton & - Vitalkapazität vermindert auf weniger als \\
- Erhöhter zentraler Venendruck (>16 mm & $1 / 3$ des Maximums \\
Wassersäule) & \\
- Zirkulationszeit $\geq 25$ sec & \\
- Hepatojugulärer Reflux & \\
- Gewichtsabnahme von über 4,5 kg in 5 & \\
Tagen unter Herzinsuffizienztherapie & \\
\hline Für die klinische Diagnose einer Herzinsuffizienz müssen zwei Kriterien 1. Ordnung oder ein \\
Kriterium 1. Ordnung und zwei Kriterien 2. Ordnung vorhanden sein. \\
\hline
\end{tabular}

Tabelle 1: Framingham-Kriterien für die klinische Diagnose einer Herzinsuffizienz (nach McKee et al. 1971)

\subsubsection{Stadieneinteilung der Herzinsuffizienz}

Zurzeit existieren zwei gängige Einteilungsklassifikationen der Herzinsuffizienz. Die Einteilung nach der New York Heart Association (NYHA) richtet sich nach der Leistungsfähigkeit der Patienten, während die Entstehung und die Progredienz der Erkrankung deutlicher durch die Klassifikation der American Heart Association (AHA) berïcksichtigt wird. 
Der Schweregrad der Herzinsuffizienz wird entsprechend der Symptomatik in Stadien I-IV nach der NYHA-Klassifikation unterteilt. Dieses Modell bezieht sich vornehmlich auf die subjektive Beschwerdesymptomatik des Patienten.

\begin{tabular}{|l|l|}
\hline NYHA-Stadium & Subjektive Beschwerden bei einer Herzinsuffizienz \\
\hline I & Beschwerdefreiheit, normale körperliche Belastbarkeit \\
\hline II & Beschwerden bei starker körperlicher Belastung \\
\hline III & Beschwerden bei leichter körperlicher Belastung \\
\hline IV & Beschwerden in $\underline{\text { Ruhe }}$ \\
\hline
\end{tabular}

Tabelle 2: Herzinsuffizienz-Stadien gemäß New York Heart Association (NYHA)

Die American Heart Association (AHA) unterscheidet ebenfalls vier Stadien, welche in ABCD-Gruppen eingeteilt werden.

ABCD-Stadien der Herzinsuffizienz der American Heart Association (Hunt et al. 2001):

- Gruppe A: Patienten ohne Symptome einer Herzinsuffizienz, aber mit Risikofaktoren für eine Herzinsuffizienz: Hypertonie, KHK, Einnahme potentiell kardiotoxischer Medikamente, Alkoholabusus, rheumatisches Fieber in der Anamnese, Kardiomyopathien in der Familienanamnese. Es liegt noch keine strukturelle Herzerkrankung vor.

- Gruppe B: keine Symptome der Herzinsuffizienz, aber Zeichen einer strukturellen Herzerkrankung, die bekanntermaßen eng mit der Entstehung einer Herzinsuffizienz assoziiert ist wie z.B. die linksventrikuläre Hypertrophie u./o. Dilatation, Hypokontraktilität, Infarktnarben u.a.

- Gruppe C: strukturelle Herzschäden in Verbindung mit aktuellen oder früheren Symptomen einer Herzinsuffizienz

- Gruppe D: Terminale Herzinsuffizienz.

Beide oben aufgeführten Stadieneinteilungen ergänzen sich zur Beurteilung der Schwere einer Herzinsuffizienz. Patienten des NYHA-Stadiums II und III gehören zur Gruppe C der AHAKlassifikation, wohingegen Patienten der Gruppe A und B der AHA-Klassifikation dem Stadium I nach NYHA entsprechen. Die Gruppen der Stadien IV und D sind identisch. 


\subsubsection{Diagnose der Herzinsuffizienz}

Eines der wichtigsten Verfahren für die Diagnosestellung einer Herzinsuffizienz ist die klinische Untersuchung eines Patienten mit Vorliegen von Symptomen und Zeichen der kardialen Insuffizienz.

Hierbei ist das Erstellen eines Elektrokardiogramms (EKG) zu nennen.

Die wichtigste nicht-invasive Methode zur Diagnosesicherung einer Herzinsuffizienz stellt die Echokardiographie dar. Vergrößerte Ventrikel oder Atrien können als erstes Anzeichen für das Vorliegen einer Herzinsuffizienz dargestellt werden. Weiterhin können durch die transthorakale Echokardiographie unter anderem die systolische und diastolische Funktion (-sstörung), die Myokarddicke und Klappenvitien beurteilt werden. Eine Aussage über die Leistungsfähigkeit des Herzens lässt sich anhand der Berechnung der Ejektionsfraktion relativ gut treffen. Die transösophageale Echokardiographie ist nicht routinemäßig notwendig, kann jedoch z.B . bei einer schlechten transthorakalen Schallbedingung hilfreich sein.

Die Magnetresonanztomographie (MRT) ermöglicht eine reproduzierbare Bestimmung des kardialen Volumens, der Wanddicken, der linksventrikulären Masse sowie Funktion und Perfusion des Herzmuskels.

\subsubsection{Therapie der Herzinsuffizienz}

Die Behandlungsziele einer Therapie umfassen die Senkung sowohl der Hospitalisierung als auch der Sterblichkeit, eine Besserung von klinischen Beschwerden und die Verminderung einer weiteren Progression der Erkrankung.

$\mathrm{Zu}$ dieser Therapie gehört die Behandlung einer arteriellen Hypertonie, die frühzeitige Revaskularisierung der Koronargefäße bei akuter Myokardischämie und Vorbeugen eines Reinfarkts, des Weiteren die Behandlung eines Diabetes mellitus und die Reduktion weiterer Risikofaktoren bei KHK sowie die Behandlung einer Myokarditis. Ebenfalls kann die Therapie einer Kardiomyopathie, von Herzrhythmusstörungen und ggf. die operative Versorgung eines bestehenden Klappenvitiums die Progression einer Herzinsuffizienz verlangsamen.

Neben der medikamentösen Therapie sollten zusätzlich Allgemeinmaßnahmen wie Gewichtsreduktion, begrenzte Kochsalzzufuhr, Nikotinkarenz und Begrenzung des Alkoholkonsums vorgenommen werden. Ein körperliches Ausdauertraining ist bei stabiler chronischer Herzinsuffizienz im NYHA-Stadium I-III zu empfehlen (Dickstein et al. 2008). 


\subsubsection{Medikamentöse Therapien der Herzinsuffizienz}

Derzeit finden unterschiedliche Medikamente und Medikamentengruppen zur Therapie der Herzinsuffizienz Verwendung. Dieser Einsatz richtet sich nach dem jeweils vorliegenden Krankheitsstadium der Herzinsuffizienz und der Verträglichkeit des Medikamentes.

Die Anwendung von ACE-Hemmern wird derzeit bei allen Patienten mit verminderter linksventrikulärer systolischer Funktion ( $\mathrm{EF} \leq 35-40 \%)$, unabhängig von deren Symptomatik (NYHA I-IV), empfohlen. Die Sterblichkeit und die Hospitalisationsrate konnten bei einer progredienten Herzinsuffizienz deutlich reduziert werden (CONSENSUS Trail Study Group 1987; SOLVD Investigators 1991).

Bei Patienten mit abgelaufenem Myokardinfarkt und mit klinischen Zeichen einer Herzinsuffizienz oder einer systolischen Dysfunktion (EF $\leq 40 \%)$ wird durch den Einsatz von ACE-Hemmern die Überlebensrate signifikant verbessert und die Rate der Reinfarkte reduziert. Die Langzeitprognose nach einem Myokardinfarkt verbessert sich unter Einsatz dieser Wirkstoffgruppe (Cleland et al. 1997; Kober et al. 1995; Pfeffer et al. 1992).

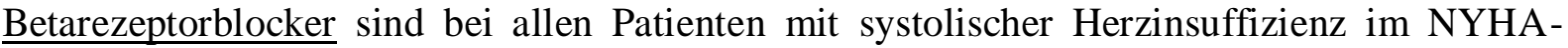
Stadium II-IV zusätzlich zur ACE-Hemmer-gabe indiziert. Auch hier werden die Gesamtsterblichkeit, die kardiovaskuläre Sterblichkeit, die Inzidenz der plötzlichen Herztode und die Todesfälle aufgrund einer Hemmung des Progresses der Herzinsuffizienz gesenkt (CIBIS-II Investigators1999; Hjalmarson et al. 2000; Krum et al. 2003; MERIT-HF Study Group 1999; Packer et al. 1996).

Bei jeder Herzinsuffizienz mit Flüssigkeitsretention (periphere Ödeme oder Lungenstauung) sind Diuretika indiziert. Wenn möglich sollten diese mit einem ACE-Hemmer kombiniert werden. Die additive Gabe von niedrig dosiertem Spirinolacton zeigte in der RALES -Studie bei schwer herzinsuffizienten Patienten (NYHA III-IV, EF $\leq 35 \%$ ) eine Verbesserung der Symptomatik und eine Reduktion der Krankenhausaufenthalte sowie die Senkung der plötzlichen Herztodrate und der Sterblichkeit infolge von Pumpversagen (Cicoira et al. 2002; Ramires et al. 2000).

Eine Therapiealternative $\mathrm{zu}$ den ACE-Hemmern, vor allem bei Auftreten von Unverträglichkeiten, stellen die AT1-Rezeptorblocker dar (Granger et al. 2003). 
Die Gabe eines Herzglykosids zusätzlich zu einer Therapie mit ACE-Hemmern, Betablockern und ggf. Diuretika bei Patienten mit Sinusryhthmus und linksventrikulärer Fehlfunktion kann die Symptomatik verbessern und die Hospitalisation aufgrund einer Herzinsuffizienz senken (Digitalis Investigation Group 1997).

\subsubsection{Komplikationen und Folgen der Herzinsuffizienz}

Die Prognose der Herzinsuffizienz wird von mehreren Faktoren, wie durch den Grad der ventrikulären Funktionsstörung, der Belastbarkeit, der Symptomatik und der Begleiterkrankungen beeinflusst (Bouvy et al. 2003).

Bei einer Herzinsuffizienz mit erhaltener Pumpfunktion ist die Prognose günstiger als bei Patienten mit systolischer Dysfunktion, im Vergleich mit dem Herzgesunden aber deutlich reduziert (Gustafsson et al. 2003).

\subsection{Definition, Prävalenz und Pathophysiologie der diastolischen Dysfunktion}

30-50\% aller Patienten mit den Symptomen einer Herzinsuffizienz leiden an einer isolierten oder vorherrschenden diastolischen Funktionsstörung bei noch normaler systolischer Ejektionsfraktion. Zwar liegt die jährliche Letalität mit $8 \%$ deutlich unter der Letalität von $19 \%$ bei Patienten mit einer systolischen Herzinsuffizienz, ist aber noch doppelt so hoch wie in einem nicht herzinsuffizienten Vergleichskollektiv. Die 1-Jahres-Mortalität liegt bei 510\%, wohingegen sie bei der systolischen Dysfunktion bei 10-20\% liegt. Die Morbidität ist vergleichbar mit der der systolischen Fehlfunktion (Vasan et al. 1995).

Eine deutliche Altersabhängigkeit ist in der Prävalenz und der Prognose zu erkennen. So zeigte die Framingham-Studie, dass Frauen häufiger an einer diastolischen Herzinsuffizienz erkranken als Männer. Um die Progression zu verhindern und die Mortalität zu senken, ist eine frühzeitige Diagnose und kausale Therapie erforderlich (Baessler et al. 2003; Gaasch und Zile 2004; Vasan et al. 1995).

Pathophysiolgisch kehren die kontrahierten Myofibrillen nur inkomplett oder nicht ausreichend schnell genug in ihre Ausgangslänge zurück. Dadurch ist es dem linken Ventrikel nicht möglich, ausreichend Blut bei niedrigen linksatrialen Drücken aufzunehmen. Dies hat zur Folge, dass die ventrikuläre Füllung unvollständig oder verlangsamt ist (Aurigemma und Gaasch 2004; Zile und Brutsaert 2002). 
Die häufigsten Ursachen einer diastolischen Dysfunktion sind neben der linksventrikulären Hypertrophie, welche meist durch eine hypertensive Herzerkrankung entsteht, die koronare Herzerkrankung sowie Diabetes mellitus oder eine Schlafapnoe. Weiterhin ist es möglich, in myokardiale und extramyokardiale Ursachen zu unterteilen. Unter die myokardialen Ursachen kann man z.B. die hypertensive Herzkrankheit und die Aortenstenose, deren Folge eine druckbelastungsinduzierte Hypertrophie ist, fassen. Eine chronische koronare Herzkrankheit oder eine akute Myokardischämie führen zu einer ischämischen Herzkrankheit, welche die Ausbildung einer diastolischen Herzinsuffizienz begünstigt. Andere myokardiale Ursachen sind die Kardiomyopathien und das Schlafapnoe-Syndrom. $\mathrm{Zu}$ den extramyokardialen Ursachen gehören Perikarderkrankungen wie die Perikaditis oder die Perikardtamponade sowie die rechtsventrikuläre Druck- oder Volumenbelastung und valvuläre Herzerkrankungen (Gaasch und Zile 2004; Zile und Brutsaert 2002).

Die klinischen Symptome und Befunde sind nicht spezifisch für die Diagnose einer diastolischen Dysfunktion. Eine Unterscheidung zwischen diastolischer und systolischer Herzinsuffizienz ist in den meisten Fällen nicht möglich, da die Symptome in ähnlicher Ausprägung vorhanden sind. So lassen sich bei beiden Erkrankungen Belastungsdyspnoe, Orthopnoe, Jugularvenenstauung, pulmonale Rasselgeräusche, 3./4. Herzton, Hepatomegalie, Ödeme oder pulmonalvenöse Stauungszeichen finden (Zile und Brutsaert 2002).

1998 schlug die European Study Group on Diastolic Heart Failure eine einheitliche Definition und diagnostische Kriterien zur Erfassung der diastolischen Dysfunktion vor.(European Study Group on Diastolic Heart Failure 1998).

Um die Diagnose einer diastolischen Herzinsuffizienz zu stellen, müssen drei Kriterien erfüllt werden:

1. Das Vorliegen von Symptomen oder Zeichen einer Stauungsinsuffizienz: Hierzu zählen Belastungsdyspnoe, Orthopnoe, Galopprhythmus, feuchte pulmonale Rasselgeräusche oder das Lungenödem.

2. Das Vorliegen einer normalen oder nur geringgradig eingeschränkten linksventrikulären systolischen Funktion: Hierzu wird eine EF $\geq 50 \%$ gefordert, zusätzlich sollte der Nachweis der EF $<72$ Stunden liegen, das heißt möglichst zeitnah zu dem akuten Ereignis einer Stauungsinsuffizienz.

3. Das Vorliegen einer linksventrikulären diastolischen Dysfunktion: Diese ist echokardiographisch oder/und invasiv-hämodynamisch nachzuweisen durch eine verzögerte 
isovolumetrische Relaxation und/oder eine verlangsamte frühdiastolische Füllung und/oder eine linksventrikuläre Dehnbarkeit und/oder eine erhöhte linksventrikuläre Steifigkeit (Vasan und Levy 2000).

Eines der Diagnosemittel ist die Herzkatheteruntersuchung. Diese invasive Methode galt bisher als Gold-Standard zur Sicherung einer diastolischen Herzinsuffizienz. Während des gesamten Herzzyklus kann eine simultane Messung von Druck, Volumen und linksventrikulärer Geometrie erfolgen. Hinweisend für eine diastolische Dysfunktion ist eine der nachfolgenden hämodynamischen Veränderungen:

- die Erhöhung des enddiastolischen Drucks (LVEDP >16mmHg) oder des pulmonalkapillären Verschlussdrucks (PCWP $>12 \mathrm{mmHg}$ ) in Ruhe

- die Verminderung der Druckabfallgeschwindigkeit (dP/dt min $<1100 \mathrm{mmHg} / \mathrm{s}$ )

- die Verlängerung der Zeitkonstante des isovolumetrischen linksventrikulären Druckabfalls, Tau (>48ms)

- die Verminderung der schnellen frühdiastolischen Füllungsrate (peak filling rate, $\mathrm{PFR}<160 \mathrm{ml} / \mathrm{s} / \mathrm{m}^{2}$ )

- die Zunahme der linksventrikulären oder myokardialen Steifigkeit. (Erbel et al. 2002).

Bisher gab es keinen einzelnen echokardiograpischen Parameter, der mit ausreichender Sicherheit eine diastolische Dysfunktion des linken Ventrikels erfasst (Vasan und Levy 2000). Mittlerweile hat sich in verschiedenen Studien gezeigt, dass sich mit Hilfe des Gewebedopplers das Verhältnis von E/E' bestimmen lässt und dieser Parameter bei einer Erhöhung auf über 15 nahezu diagnostisch beweisend für das Vorliegen einer linksventrikulären diastolischen Dysfunktion ist. Dieses hat bereits Einzug in das Consensus Statement der ESC erhalten (Paulus et al. 2007).

Echokardiographisch lässt sich die diastolische Funktion in 4 Schweregrade (nach der American Society of Echocardiography) einteilen, welche eine erhebliche prognostische Bedeutung haben (Erbel et al. 2002).

\section{- Grad 0 Normales Füllungsmuster}

Gemessen wird dabei die Flussgeschwindigkeit der schnellen Füllung des linken Ventrikels (E) und der aktiven Füllung durch die atriale Kontraktion (A). Als Summenparameter für die diastolische Funktion wird das E/A-Verhältnis (>1) gebildet. 


\section{- Grad I Verzögerte Relaxation}

Charakteristisch für dieses Stadium ist ein $\mathrm{E} / \mathrm{A}-$ Verhältnis $(\mathrm{E} / \mathrm{A}<1)$. Es wird bei Patienten mit reduzierter linksventrikulärer Relaxation bei noch relativ normaler Compliance und nicht erhöhten Füllungsdrücken beobachtet. Zusätzlich findet sich während der frühen ventrikulären Füllung eine Verlängerung der isovolumetrischen Relaxationszeit (IVRT >100ms) und Dezelerationszeit (DT >220ms).

- Grad II Pseudonormalisierung

Dieses Stadium gleicht in vielen Aspekten dem normalen Füllungsmuster und ist daher schwierig zu differenzieren. Die Compliance des linken Ventrikels und die frühe Relaxation sind vermindert. Es kommt zu einer Zunahme der Wandspannung. Des Weiteren ist der Füllungsdruck kompensatorisch erhöht, um das Schlagvolumen aufrecht zu erhalten. Das E/A-Verhältnis ist >1, da die Kontraktion des linken Atriums vermindert ist. Eine Umkehr unter Valsalva oder Nitro-Gabe ermöglicht vor allem die reduzierte Geschwindigkeit der Flusspropagation der initialen Füllung in den linken Ventrikel $(\mathrm{Vp}<45 \mathrm{~cm} / \mathrm{s})$ sowie die niedrige frühdiastolische Mitralanulusgeschwindigkeit $\left(E^{\prime}<8 \mathrm{~cm} / \mathrm{s}\right)$ im Gewebedoppler, um das Stadium 2 vom normalen Füllungsmuster abzugrenzen.

- Grad III Restriktives Füllungsmuster

Die Symptome einer manifesten Herzinsuffizienz sind ausgeprägt. Das E/A-Verhältnis ist $>2$, DT $<150 \mathrm{~ms}$, IVRT <60ms, des Weiteren fallen Vp und $\mathrm{E}^{\prime}$ weiter ab. (Erbel et al. 2002; Voelker 2004)

Für die Prognose der diastolischen Dysfunktion ist es wichtig, zwischen einer reversiblen (Stadium IIIa) und einer irreversiblen restriktiven Funktionsstörung (Stadium IIIb) zu unterscheiden. Durch die Gabe eines Vasodilatators ändert sich bei einer reversiblen Störung die Restriktion in eine Pseudonormalisierung (Grad II), dies geschieht bei einer irreversiblen Störung nicht (Pozzoli et al. 1997). 


\subsection{Natriuretische Peptide}

\subsubsection{Entdeckung}

Es sind bisher vier natriuretische Peptide bekannt: ANP, BNP, CNP und DNP.

ANP (atriales natriuretisches Peptid) wurde 1981 erstmals beschrieben (De Bold et al. 1981).

1988 gelang es, BNP aus Schweinegehirn zu extrahieren. Es gehört ebenfalls in die Familie der Polypeptide mit natriuretischen Eigenschaften (Sudoh et al. 1988).

CNP wurde ähnlich wie das BNP aus dem zentralnervösen System extrahiert. Erst später stellte man fest, dass CNP in hohen Konzentrationen von Gefäßendothelien sezerniert wird (Sudoh et al. 1990).

DNP wird als bisher letztes Mitglied der Familie der natriuretischen Peptide benannt (Stein und Levin 1998).

\subsubsection{Freisetzung, physiologische Bedeutung und Metabolismus der natriuretischen Peptide}

Die ersten drei natriuretischen Peptide ANP, BNP und CNP ähneln sich in der Struktur. Sie bestehen aus einem 17 Aminosäuren langen zentralen Ring und einem für jedes Peptid variablen C-terminalen bzw. N-terminalen Ende (Nakao et al. 1992).

ANP, bestehend aus 28 Aminosäuren, wird im Atrium des Herzens in Granula gespeichert und bei Bedarf sezerniert.

Das aus 32 Aminosäuren zusammengesetzte BNP wird überwiegend im Ventrikel gebildet und nur in geringen Mengen gespeichert. Bei Zunahme der enddiastolischen linksventrikulären Wandspannung und vom Füllungszustand abhängig wird es sezerniert. Es induziert über seine systemische Wirkung eine Natriurese, Diurese und fungiert als Vasodilatator. Die Aktivierung des RAAS-Systems und die des Endothelins wird durch das BNP unterdrückt. Des Weiteren kommt es durch die Wirkung des BNP zu einer direkten Hemmung der sympathischen vasokonstriktorischen Hormonsysteme und infolgedessen zu einer Senkung des peripheren Gefäßwiderstandes (Sudoh et al. 1988). 
Das BNP-Gen, bestehend aus 3 Exons und 2 Introns, wurde auf dem kurzen distalen Arm von Chromosom 1 lokalisiert (Tamura et al. 1996).

BNP wird von Myozyten als prä-proBNP (134 AS) gebildet. Durch weiteres Processing entsteht pro-BNP (108 AS). Während der Sekretion aus den Myozyten wird proBNP in die physiologische aktive Form BNP (77-108 AS; 32 AS) und ein inaktives aminoterminales Spaltprodukt NT-proBNP (1-76 AS) separiert (Valli et al. 1999).

Aus dem Kreislauf wird das BNP über Rezeptoren, NT-proBNP über die Niere eliminiert. Bei eingeschränkter Nierenfunktion ist NT-proBNP erhöht (Luchner et al. 2002).

Die Plasmahalbwertzeit von BNP liegt bei 22 Minuten, die von NT-proBNP bei 120 Minuten (Holmes et al. 1993; Roche Diagnostics 2002).

Die natriuretischen Peptide stellen einen physiologischen Antagonismus zum Angiotensin II dar und hemmen somit die Sekretion von Aldosteron und die tubuläre Resorption von Natrium in der Niere (Wilkins et al. 1997).

Der Blutdruck, das Herzzeitvolumen sowie der linksventrikuläre endsystolische Druck und der totale periphere Widerstand werden durch ANP und BNP gesenkt. Hierbei ist die Wirkung des BNP ausgeprägter als die des in den Vorhöfen gebildeten ANPs (Kelly und Struthers 2001).

Es sind drei verschiedene Rezeptoren für die natriuretischen Peptide bekannt. Die Nomenklatur A, B und C lässt dabei nicht auf die Affinität zum jeweiligen Peptid schließen. Die Rezeptoren wurden im Nierengewebe, im Herz, im vaskulären Endothel, in den Nebennieren und im Zentralnervensystem nachgewiesen. Es handelt sich um transmembranäre Proteine der Guanylcyclase-Familie. Der Abbau der natriuretischen Peptide erfolgt im Wesentlichen über zwei Mechanismen: durch NPR-C-Rezeptor-vermittelte Endozytose gefolgt von lysosomaler Degradation werden die natriuretischen Peptide eliminiert. Einen weiteren Mechanismus stellen die membrangebundenen unspezifischen, neutralen Endopeptidasen in den Nieren und dem Gefäßsystem dar. Mit Hilfe der Endopeptidase werden die natriuretischen Peptide gebunden und ihre Ringstruktur aufgespalten. Durch beide Mechanismen werden sie inaktiv (Valli et al. 1999). 


\subsubsection{Natriuretische Peptide und ihre Bedeutung für die kardiovaskuläre Diagnostik}

Wie durch die SOLVD- oder die SAVE-Studie gezeigt wurde, bestand in den letzten Jahren ein großes Interesse an zirkulierendem BNP zur Erkennung und Diagnose einer systolischen Funktionsstörung bei Patienten mit kardiovaskulären Risikofaktoren.

Es konnte gezeigt werden, dass bei gesunden 85-jährigen Probanden die Plasmakonzentration von BNP signifikant $(\mathrm{p}<0,001)$ höher war als bei einer 40-jährigen Vergleichsgruppe. Unterschiede zwischen Männern und Frauen konnten in der Altersgruppe der 85-jährigen nicht nachgewiesen werden. Jedoch konnten deutlich erhöhte Konzentrationen bei Patienten mit Herzinsuffizienz, ischämischer Kardiomyopathie und Vorhofflimmern nachgewiesen werden (Wallén et al. 1997).

Des Weiteren konnte gezeigt werden, dass die natriuretischen Peptide, vor allem ANP und BNP, exzellente Marker für die Diagnostik und für das Erkrankungsrisko einer Herzinsuffizienz sind (McDonagh et al. 1998; McDonagh et al. 2004; Berger et al. 2002; Andersson und Hall 2000; Hülsmann et al. 2002).

Für BNP und sein N-terminales Fragment NT-pro BNP konnte gezeigt werden, dass sie sich möglicherweise als Marker für die asymptomatische linksventrikuläre systolische und/oder diastolische Ventrikelfunktionsstörung eignen (Davis et al. 1994; Krishnaswamy et al. 2001; Bay et al. 2003; Morrison et al. 2002; Lubien et al. 2002).

Informationen über die Vergleichbarkeit von NT-proANP, NT-proBNP und BNP hinsichtlich der Diagnose der systolischen/diastolischen Ventrikelfunktionsstörung bei Patienten mit Risikofaktoren für die Entwicklung einer Herzinsuffizienz, aber ohne aktuelle klinische Zeichen einer Herzinsuffizienz, sind limitiert.

Es existieren nur spärliche Informationen betreffend die Plasmakonzentration der natriuretischen Peptide in unterschiedlichen Stadien der diastolischen und der systolischen Dysfunktion, speziell bei Patienten, die keine Symptome der Herzinsuffizienz aufweisen.

In einer Studie von Yamada et al. konnte eine positive Korrelation zwischen der Plasmakonzentration von BNP und dem linksventrikulären enddiastolischen Durchmesser 
sowie dem linksventrikulären endsystolischen Durchmesser aufgezeigt werden. Es zeigt sich eine inverse Korrelation mit der linksventrikulären Ejektionsfraktion (Yamada et al. 1997).

Da Patienten mit einer asymptomatischen linksventrikulären Funktionsstörung von einer frühen medikamentösen Therapie profitieren können, könnten im Rahmen der weiteren Diagnostik die natriuretischen Peptide als einfach durchzuführender Screening-Test eingesetzt werden.

Für die weitere diagnostische Vorgehensweise sind die Laborparameter wie Blutbild, Serumelektrolyte, Kreatinin, Glukose, Serumlipide, Leberenzyme, Urinstatus und C-reaktives Protein zur Beurteilung von Begleiterkrankungen unerlässlich. Wichtig ist die Beurteilung der Nierenfunktion vor und während der Therapie der Herzinsuffizienz. Erniedrigte Plasmakonzentration von BNP bzw. NT-proBNP können eine Herzinsuffizienz als Ursache der Symptome weitgehend ausschließen. Die Bestimmung von BNP und NT-proBNP hat derzeit einen hohen Stellenwert für die Diagnosestellung einer Herzinsuffizienz (Mu eller C et al. 2004), da sich bei Patienten mit einer chronischen Herzinsuffizienz durchschnittlich höhere BNP-Plasmakonzentrationen finden als bei Patienten ohne chronische Herzinsuffizienz (Dao et al. 2001).

\subsection{Arbeitshypothese der vorliegenden Untersuchung}

Die Plasmakonzentration von NT-proANP, NT-proBNP und BNP ist bei herzinsuffizienten Patienten erhöht. Durch die Zunahme der atrialen Wandspannung kommt es zum Anstieg der NT-proANP-Sekretion, und bei einer zunehmenden ventrikulären Wandspannung zu einer Erhöhung der NT-proBNP bzw. BNP Sekretion. Da eine Zunahme der diastolischen Dysfunktion mit Veränderungen der Wandspannung einhergeht, ändert sich das Verhältnis von NT-proBNP/NT-proANP.

Das Ziel dieser Arbeit war die Festlegung der diagnostischen Wertigkeit der natriuretischen Peptide zur Identifikation von Patienten mit asymptomatischer systolischer oder diastolischer Dysfunktion. Zusätzlich wurde die Effizienz der unterschiedlichen Screening- Modelle auf Grundlage der Plasmakonzentration der natriuretischen Peptide sowie klinischer Informationen zur Aufdeckung der präklinischen ventrikulären Dysfunktion verglichen. 


\section{MATERIAL UND METHODEN}

Im Rahmen der Vorbereitungen dieser klinischen Studie wurde ein Antrag zur Prüfung bei der zuständigen Ethikkommission eingereicht und genehmigt.

\subsection{Rekrutierung der Patienten}

Vom 15. Januar 2003 bis zum 15. Juli 2004 erfolgte die Rekrutierung der Patienten über Hausärzte der Region Göttingen und Umgebung.

Einschlusskriterien waren der arterielle Hypertonus, Diabetes mellitus, positive Familienanamnese in Bezug auf die Herzinsuffizienz sowie eine bekannte koronare Herzerkrankung. So wurden 542 Patienten mit dem Risiko einer diastolischen Herzinsuffizienz, aber ohne vordiagnostizierte systolische oder diastolische Dysfunktion und ohne klinische Zeichen einer Herzinsuffizienz, untersucht. Patienten wurden in die Studie einbezogen wenn eine arterielle Hypertonie von dem behandelten Hausarzt diagnostiziert wurde oder wenn sie antihypertensiv therapiert wurden. Als Diabetiker wurden Patienten klassifiziert, bei denen die Diagnose bereits vom Hausarzt gestellt worden war oder eine antidiabetische Therapie vorlag. Die koronare Herzerkrankung wurde festgelegt durch eine angiographisch gesicherte koronare Herzerkrankung, vorausgegangene Revaskularisierungen oder vorausgegangenen Herzinfarkt.

Eine bereits bestehende Herzinsuffizienz und eine nicht bestehende Volljährigkeit wurden als Ausschlusskriterien definiert.

Der Studienablauf wurde unter streng kontrollierten Bedingungen durchgeführt (regulärere Medikamenteneinnahme, kein Nikotin, Verzicht auf Kaffee oder schwarzen Tee). Eine Aufklärung über den Studieninhalt sowie eine schriftliche Einwilligung der Patienten waren Voraussetzung zur Teilnahme an der Studie.

\subsection{Anamnese}

Die Krankengeschichte und subjektive Symptome einer Herzinsuffizienz wurden mit Hilfe eines „Case-Report“-Formulars erfasst. Dabei wurden neben kardiologischen Vorerkrankungen wie Myokardinfarkt auch pulmonale Erkrankungen wie Asthma bronchiale 
und chronisch obstruktive Lungenerkrankungen erfragt. Eine vollständige Familienanamnese in Bezug auf koronare Herzerkrankung und Herzinsuffizienz wurde erhoben und zusätzlich zerebro- vaskuläre und peripher-vaskuläre Erkrankungen erfasst. Des Weiteren wurden die Patienten nach ihren Alkohol- und Nikotingewohnheiten befragt. Zusätzlich wurde eine genaue Medikamentenanamnese erhoben.

\subsection{Körperliche Untersuchung}

Bei allen Studienpatienten wurde eine allgemeine körperliche Untersuchung durchgeführt, hierbei lag der Schwerpunkt auf dem kardiopulmonalen Status wie Auskultation des Herzens und Beurteilung der Herztöne sowie Auskultation und Perkussion der Lunge. Zusätzlich wurde der neurologische Status der Patienten erfasst. Des Weiteren wurde bei jedem Patienten der Blutdruck gemessen, das Gewicht bestimmt, Körperoberfläche und Body-Mass-Index berechnet.

\subsection{Blutentnahme und Probenbearbeitung}

Die Blutentnahme aller Patienten der Studie erfolgte unter standardisierten Bedingungen. Nach einer Liegezeit von 30 Minuten mit leicht erhöhtem Oberkörper, um orthostatische und Belastungseinflüsse auf die Freisetzung von BNP und NT-proBNP zu vermeiden, erfolgte die Blutentnahme am Unterarm mit einer 0,80 x $20 \mathrm{~mm}$ Butterflykanüle am gleichen Tag wie die echokardiographische Untersuchung.

Das Blut wurde anschließend bei 3500 Umdrehungen pro Minute in einer Zentrifuge für 10 Minuten bei 2340 g zentrifugiert. Danach wurde das Serum abpipettiert, in Aliquots portioniert und bei $-70^{\circ} \mathrm{C}$ tiefgefroren.

Das NT-proANP wurde per Sandwich Immunoassay (Immundiagnostik, Bensheim) sowie Milenia-Mikrotiter-Plattenleser bestimmt. NT-proBNP sowie BNP wurden durch eine Sandwich Chemilumineszenz Immunoassay mittels Elexsys 2010® (Roche Diagnostics, Mannheim) bzw. Centaur (Bayer Vital, Leverkusen) bestimmt.

So wurden die NT-proBNP-Konzentrationen aus EDTA-Plasma im vollautomatischen RocheImmunoassay-Analyseautomaten Elecsys 2010 gemäß den Angaben des Hersteller-Protokolls 
ermittelt. Dabei erkennen Ruthenium-markierte und biotinylierte polyklonale Antikörper unterschiedliche Epitope, zum einen der $\mathrm{N}$-terminalen und zum anderen der C-terminalen Region des zu bestimmenden NT-proBNP-Moleküls. Beide Antikörper bilden einen Sandwichkomplex. Nach Zugabe von Streptavidin-beschichteten Mikropartikeln wird der Komplex an die Festphase gebunden. Das Reaktionsgemisch wird in die Messzelle überführt, in welcher die Mikropartikel durch magnetische Wirkung auf die Oberfläche der Elektrode fixiert werden. Durch Spannungsanlegung wird die Chemilumineszenz-Emission induziert und mit Hilfe des Photomultipliers gemessen. Der Messbereich liegt zwischen 5 und 35000 $\mathrm{pg} / \mathrm{ml}$. Die Umrechnung in pmol/ml erfolgte durch folgende Formel:

$$
(\mathrm{pmol} / \mathrm{ml}) * 8,475=(\mathrm{pg} / \mathrm{ml})
$$

Die Referenzbereiche von NT-proBNP liegen für Männer <50 Jahre bei $84 \mathrm{pg} / \mathrm{ml}$, bei Männern >50 Jahre bei 194 pg/ml. Bei Frauen <50 Jahre bei 155 pg/ml und bei >50 Jahren bei $222 \mathrm{pg} / \mathrm{ml}$. Die funktionale Sensitivität wird mit $<50 \quad \mathrm{pg} / \mathrm{ml} \quad(<5,9 \mathrm{pmol} / \mathrm{l})$ angegeben(Roche Diagnostics 2002). Alle Messungen wurden hierbei zweifach nach Empfehlungen der Hersteller durchgeführt.

\subsection{EKG}

Ein 12-Kanal-EKG wurde bei allen Patienten mit dem CS-200 der Firma Schiller geschrieben. Standardableitungen nach Eindhoven und Goldberger sowie Brustwandableitungen nach Wilson wurden erfasst.

Die hauptsächlich beurteilten Parameter waren Herzfrequenz und Rhythmusstörungen. Auch wurden Erregunsleitungsstörungen wie Blockbilder unterschiedlicher Ausprägung analysiert. Die linksventrikulären Hypertrophiezeichen wurden nach dem Lewis- und Sokolow-Index berechnet.

$$
\begin{aligned}
& \text { Lewis }(>1,6 \mathrm{mV})=\mathrm{R}_{\mathrm{I}}+\mathrm{S}_{\mathrm{III}}-\mathrm{S}_{\mathrm{I}}-\mathrm{R}_{\mathrm{III}} \\
& \text { Sokolow }(>3,5 \mathrm{mV})=\mathrm{S}_{\mathrm{V} 1}+\mathrm{R}_{\mathrm{V} 6} \text { oder } \mathrm{S}_{\mathrm{V} 2}+\mathrm{R}_{\mathrm{V} 5}
\end{aligned}
$$




\subsection{Echokardiographie}

Die transthorakale Echokardiographie wurde bei allen Patienten von erfahrenen Kardiologen mit dem Sonos Agilent 5500 der Firma Phillips in Verbindung mit einem 3,5-MegahertzSchallkopf gemäß den Standardtechniken der American Society of Echocardiography durchgeführt (Cheitlin et al. 2003).

Eine Ejektionsfraktion (EF) $<50 \%$, bestimmt nach Simpson (monoplan), wurde als systolische Dysfunktion definiert. Bei Patienten mit einer normalen Ejektionsfraktion (EF>50\%) wurde überprüft, ob sie entsprechend einer diastolischen Dysfunktion eingestuft werden konnten (Quinones et al. 2002).

Die E-Welle und A-Welle sowie die E-Dezelerationszeit wurden durch Messung der transmitralen Füllungsgeschwindigkeiten an der Mitralklappenspitze bestimmt. Die Isovolumetrische Relaxationszeit (IVRT) konnte im apikalen 5-Kammer-Blick erfasst werden. Das pulmonalvenöse Flussprofil wurde in der rechten oberen Pulmonalvene ermittelt und das Verhältnis des positiven systolischen Einstromes und des positiven diastolischen Einstromes (S/D) analysiert. Die Geschwindigkeit der Flusspropagation (Vp) wurde in der Mitralklappenmitte im Color Doppler M-Mode gemessen.

Mittels Darstellungen des Gewebedopplers am septalen Rand des Mitralklappenringes wurden die Geschwindigkeiten der frühen (E')und der späten ( $\left.\mathrm{A}^{\prime}\right)$ Diastole abgeleitet.

Die diastolische Dysfunktion wurde folgendermaßen klassifiziert:

Normale diastolische Funktion: $1<\mathrm{E} / \mathrm{A}<2 ; 150 \mathrm{~ms}<\mathrm{E}_{\text {Decel }}<280 \mathrm{~ms}$; IVRT $<105 \mathrm{~ms}$; S/D $>1$; $E^{\prime}>8 \mathrm{~cm} / \mathrm{s} ; \mathrm{Vp}>45 \mathrm{~cm} / \mathrm{s}$.

Milde diastolische Dysfunktion: E/A $<1 ; E_{\text {Decel }}>280 \mathrm{~ms} ; \mathrm{IVRT}>105 \mathrm{~ms} ; \mathrm{S} / \mathrm{D}>1 ; \mathrm{E}^{\prime}<8 \mathrm{~cm} / \mathrm{s}$; $\mathrm{Vp}<45 \mathrm{~cm} / \mathrm{s}$.

Moderate diastolische Dysfunktion: $1<\mathrm{E} / \mathrm{A}<2 ; 150 \mathrm{~ms}<\mathrm{E}_{\text {Decel }}<200 \mathrm{~ms} ; 60 \mathrm{~ms}<\mathrm{IVRT}<105$ $\mathrm{ms} ; \mathrm{S} / \mathrm{D}<1 ; \mathrm{E}^{\prime}<8 \mathrm{~cm} / \mathrm{s} ; \mathrm{Vp}<45 \mathrm{~cm} / \mathrm{s}$.

Schwere diastolische Dysfunktion: Restriktives Füllungsmuster (E/A> 2) oder echokardiographische Zeichen einer diastolischen Dysfunktion in Kombination mit zwei nachfolgenden Zeichen. Hierzu gehörte eine Erhöhung des Füllungsdruckes E/E'>15 mit Andeutung eines erhöhten LVEDP und eine Erhöhung des linksatrialen Durchmessers von $>45$ mm (Nagueh et al. 2004; Paulus et al. 2007; Rossi et al. 2006). 
Es wurden 3 Kategorien der diastolischen Dysfunktion nach Richtlinien der American Society of Echocardography (ASE) definiert.

1. Beeinträchtigte Relaxation (E/A-Verhältnis $<1$ oder 0,$5 ; \mathrm{E}^{\prime}<8 \mathrm{~cm} / \mathrm{s} ; \mathrm{E}_{\text {Decel }}>230$ oder 280 ms; Isovolumetrische Relaxationszeit (IVRT) >105 ms; vermehrte Flussgeschwindigkeit (Vp) $<45 \mathrm{~cm} / \mathrm{s}$ und systolisch-dominanter Pulmonalvenenfluss)

2. Pseudonormal (E/A-Verhältnis 1-2; $\mathrm{E}^{\prime}<8 \mathrm{~cm} / \mathrm{s} ; \mathrm{E}_{\text {Decel }} 150-200 \mathrm{~ms}$; isovolumetrische Relaxationszeit (IVRT) 60-100 ms; vermehrte Flussgeschwindigkeit (Vp) $<45 \mathrm{~cm} / \mathrm{s}$ und diastolisch-dominanter Pulmonalvenenfluss)

3. Restriktive Füllung (E/A-Verhältnis $>2 ; \mathrm{E}^{\prime}<8 \mathrm{~cm} / \mathrm{s} ; \mathrm{E}_{\text {Decel }} \leq 150 \mathrm{~ms}$; isovolumetrische Relaxationszeit (IVRT) $<60 \mathrm{~ms}$; vermehrte Flussgeschwindigkeit (Vp) $<45 \mathrm{~cm} / \mathrm{s}$ und diastolisch-dominanter Pulmonalvenenfluss) (Erbel et al. 2002; Garcia et al. 1998; Voelker 2004)

\subsection{Statistische Analyse}

Die gesammelten Daten wurden mit Hilfe der SAS 9.1 Software (SAS Institute Inc., Cary, NC, USA) analysiert. Die klinischen Parameter wurden mittels \pm Standardabweichung (s) angegeben. Kategorische Variablen wurden als Prozentwerte beschrieben. Da die natriuretischen Peptide nicht normal verteilt sind, wurden die entsprechenden Plasmaspiegel zur Durchführung der Regressionsanalysen logarithmiert. Unterschiede in den Variablen, welche als eine normale Verteilung betrachtet werden konnten, wurden durch die Analyse der Abweichungen (ANOVA; analysis of variance) verglichen, wodurch die angezeigten $\mathrm{p}$-Werte durch die Bonferroni-Korrektur für die Vielzahl angepasst wurden. Für Unterschiede der Variablen wurde der Mann-Whitney-U-Test benutzt. Effekte von Covariaten wurden durch multivariate, schrittweise, logistische Analyse der Plasmawerte der natriuretischen Peptide und der unterschiedlichen Risikofaktoren als primäre Vorhersage sowie echokardiographische Parameter der linksventrikulären Dysfunktion als Ergebnisparameter festgesetzt. Ergebnisse von $\mathrm{p}<0,05$ wurden als statistisch signifikant gewertet.

Die Sensitivität und Spezifität von NT-proANP, NT-proBNP und BNPPlasmakonzentrationen sowie das NT-proBNP/NT-proANP-Verhältnis, GFR, Alter und den entwickelten Risikostand zum Auffinden von Patienten mit echokardiograpischer bestimmbarer systolischer Dysfunktion, diastolischer Dysfunktion, schwerer diastolischer Dysfunktion und schwerer diastolischer oder systolischer Dysfunktion wurde mit Hilfe von 
„Receiver Operating Characteristics“-Analysen (ROC-Analysen) berechnet. Die Ergebnisse wurden als AUC (area under the curve) und als 95\%-Konfidenzintervall der AUC angegeben. Der optimale „cut-off” für jeden Endpunkt wurde nach den Youden-Kriterium gewählt (Youden 1950).

Der entwickelte Score wurde mittels der Leave-One-Out-Kreuzvalidierung überprüft. Bei der einfachen Kreuzvalidierung wird die zur Verfügung stehende Datenmenge, bestehend aus N Instanzen, in $\mathrm{k}$ Teilmengen $(\mathrm{k}<=\mathrm{N})$ aufgeteilt. Nach $\mathrm{k}$ Testdurchläufen errechnet sich die Gesamtfehlerquote als Durchschnitt der Einzelfehlerquoten der k Einzeldurchläufe. Bei der Leave-One-Out-Kreuzvalidierung handelt es sich um einen Spezialfall der k-Fachen Kreuzvalidierung. Hierbei ist $\mathrm{k}=\mathrm{N}$, somit werden $\mathrm{N}$ Durchläufe gestartet und deren Einzelfehlerwerte ergeben als Mittelwert die Gesamtfehlerquote (Hawkins et al. 2003; Johnston und Seshia 1992). 


\section{ERGEBNISSE}

\subsection{Patientencharakteristika}

Es wurden 542 Patienten (313 Männer, 229 Frauen; Alter 63 \pm 11 Jahre) untersucht. Die

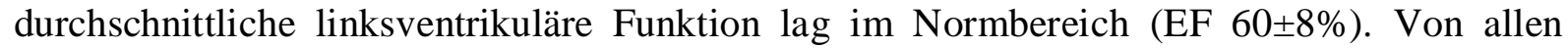
Patienten hatten 23 (4,2\%) eine systolische Dysfunktion (EF <50\%) und 352 (65\%) Patienten zeigten echokardiographische Kriterien einer isolierten diastolischen Dysfunktion. Bei 167 (31\%) der untersuchten Patienten konnte eine normale linksventrikuläre Funktion, also weder eine systolische noch eine diastolische Dysfunktion, festgestellt werden. Von den 352 Patienten mit einer isolierten diastolischen Dysfunktion zeigten 15 eine schwere, 45 eine moderate und 292 Patienten eine milde Form der diastolischen Dysfunktion.

\begin{tabular}{|l|c|c|c|c|}
\hline Charakteristika/Patienten & Gesamt & $\begin{array}{c}\text { Normale } \\
\text { Funktion }\end{array}$ & EF <50\% & $\begin{array}{c}\text { Diastolische } \\
\text { Dysfunktion }\end{array}$ \\
\hline $\mathrm{N}$ & 542 & 167 & 23 & 352 \\
\hline Alter, Jahre $\pm \mathrm{s}$ & $63 \pm 11$ & $58 \pm 12$ & $69 \pm 8^{*}$ & $64 \pm 10^{*}$ \\
\hline Männlich, \% & 58 & 56 & 70 & 58 \\
\hline Diabetes, \% & 31 & 28 & 39 & 32 \\
\hline Bekannte KHK, \% & 30 & 23 & $65^{*}$ & 31 \\
\hline Rauchen py $\pm \mathrm{s}$ & $14 \pm 19$ & $13 \pm 18$ & $17 \pm 21$ & $14 \pm 20$ \\
\hline Septumdicke mm $\pm \mathrm{s}$ & $12 \pm 2$ & $12 \pm 2$ & $12 \pm 2$ & $12 \pm 2^{*}$ \\
\hline Hinterwanddicke mm $\pm \mathrm{s}$ & $11 \pm 2$ & $11 \pm 2$ & $12 \pm 1$ & $12 \pm 2^{*}$ \\
\hline $\begin{array}{l}\text { Linksventrikuläre Masse, g, } \\
\text { Median [25-75 Percentile] }\end{array}$ & $234[194-276]$ & $220[157-297]$ & $257[214-352]^{*}$ & $238[169-319]^{*}$ \\
\hline LVEDD (mm) & $51 \pm 5$ & $51 \pm 5$ & $56 \pm 6^{*}$ & $51 \pm 5$ \\
\hline LA (mm) & $41 \pm 6$ & $40 \pm 6$ & $46 \pm 7^{*}$ & $41 \pm 5$ \\
\hline EF \% $\pm \mathrm{s}$ & $60 \pm 8$ & $61 \pm 7$ & $41 \pm 8^{*}$ & $61 \pm 7$ \\
\hline Diastolische Dysfunktion, \% & 71 & 0 & $93^{*}$ & $100^{*}$ \\
\hline GFR (ml/min) & $82 \pm 18$ & $86 \pm 20$ & $77 \pm 23$ & $80 \pm 17^{*}$ \\
\hline Body-mass-Index, kg/m ${ }^{2} \pm \mathrm{s}$ & $29 \pm 5$ & $30 \pm 5$ & $29 \pm 4$ & $29 \pm 4$ \\
\hline
\end{tabular}

Tabelle 3: Klinische Charakteristika der Studienpatienten

$*<0,05$ vs. normale Funktion 


\subsection{NT-proANP-Plasmakonzentration bei Patienten mit normaler linksventrikulärer Funktion}

Die mediane NT-proANP-Plasmakonzentration in der Studienpopulation lag bei 3191 $\mathrm{fmol} / \mathrm{ml}[2309-4483 \mathrm{fmol} / \mathrm{ml}]$.

Patienten mit normaler linksventrikulärer Funktion hatten einen NT-proANP-Wert von 2880 [2242-3927] fmol/ml, wohingegen Patienten mit einer leichten diastolischen Dysfunktion eine Plasmakonzentration von 2995 [2212-4190] fmol/ml aufwiesen. Die in der Studie untersuchten Patienten mit einer mäßigen/schweren diastolischen Dysfunktion hatten eine erhöhte mediane NT-proANP-Konzentration von 4212 [2824-5095] fmol/ml ( $p<0,01$ vs. normal und milder diastolischer Dysfunktion). Ein mittlerer Plasmaspiegel von 5465 [38578045] fmol/ml wurde bei Patienten mit einer systolischen Dysfunktion festgestellt ( $\mathrm{p}<0,01$ vs. normal und vs. milder diastolischer Dysfunktion).

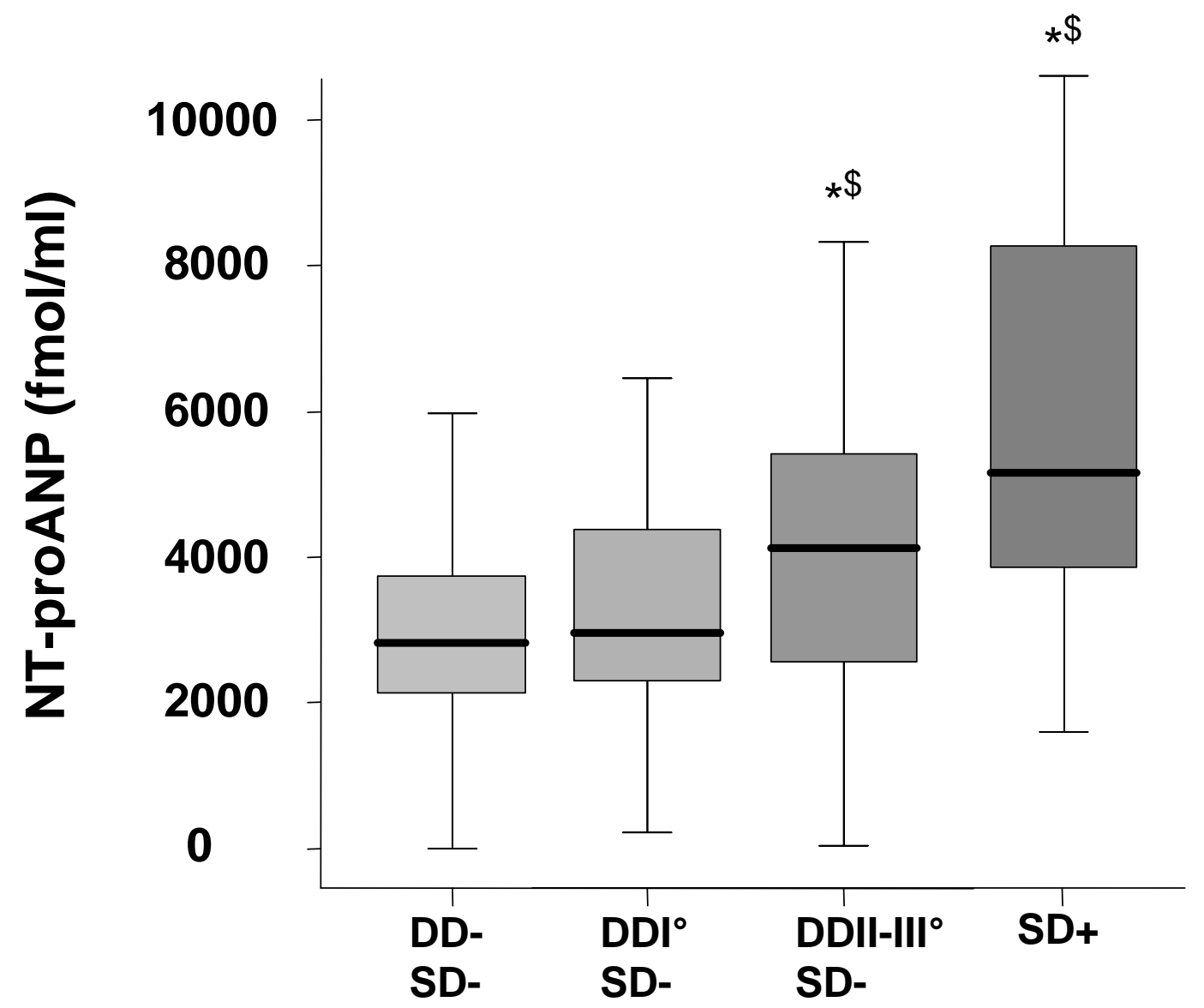

Abbildung 1: Mediane NT-proANP-Plasmakonzentration bei Patienten mit normaler ventrikulärer Funktion (DD- SD-), milder $\left(\mathrm{DDI}^{\circ}\right)$, mäßiger/schwerer diastolischer Dysfunktion (DDII-III ${ }^{\circ}$ ) und systolischer Dysfunktion (SD+). *p<0,05 vs. normaler linksventrikulärer Funktion. $\$ \mathrm{p}<0,001$ vs. milder diastolischer Fehlfunktion. 


\subsection{BNP-Plasmakonzentration bei Patienten mit normaler linksventrikulärer Funktion}

Die mediane BNP-Plasmakonzentration lag in dieser Studie bei 35 pg/ml [17-66 pg/ml].

Die Patienten mit einer normalen linksventrikulären Funktion hatten einen medianen BNPPlasmaspiegel von 33 [16-61] pg/ml. Dem gegenüber standen Patienten mit einer milden diastolischen Dysfunktion, welche einen medianen BNP-Wert von 37 [18-67] pg/ml (p=0,002 vs. normal) aufwiesen. Bei Patienten mit einer moderaten/schweren diastolischen Dysfunktion ( $p<0,01$ vs. normal und milder diastolischer Dysfunktion) lag der BNP-Wert bei 57 [30-105] $\mathrm{pg} / \mathrm{ml}$ und bei Patienten mit einer systolischen Dysfunktion ( $\mathrm{p}<0,001$ vs. normaler und vs. milder und moderater/schwerer diastolischer Dysfunktion) bei 109 [32-196] pg/ml.

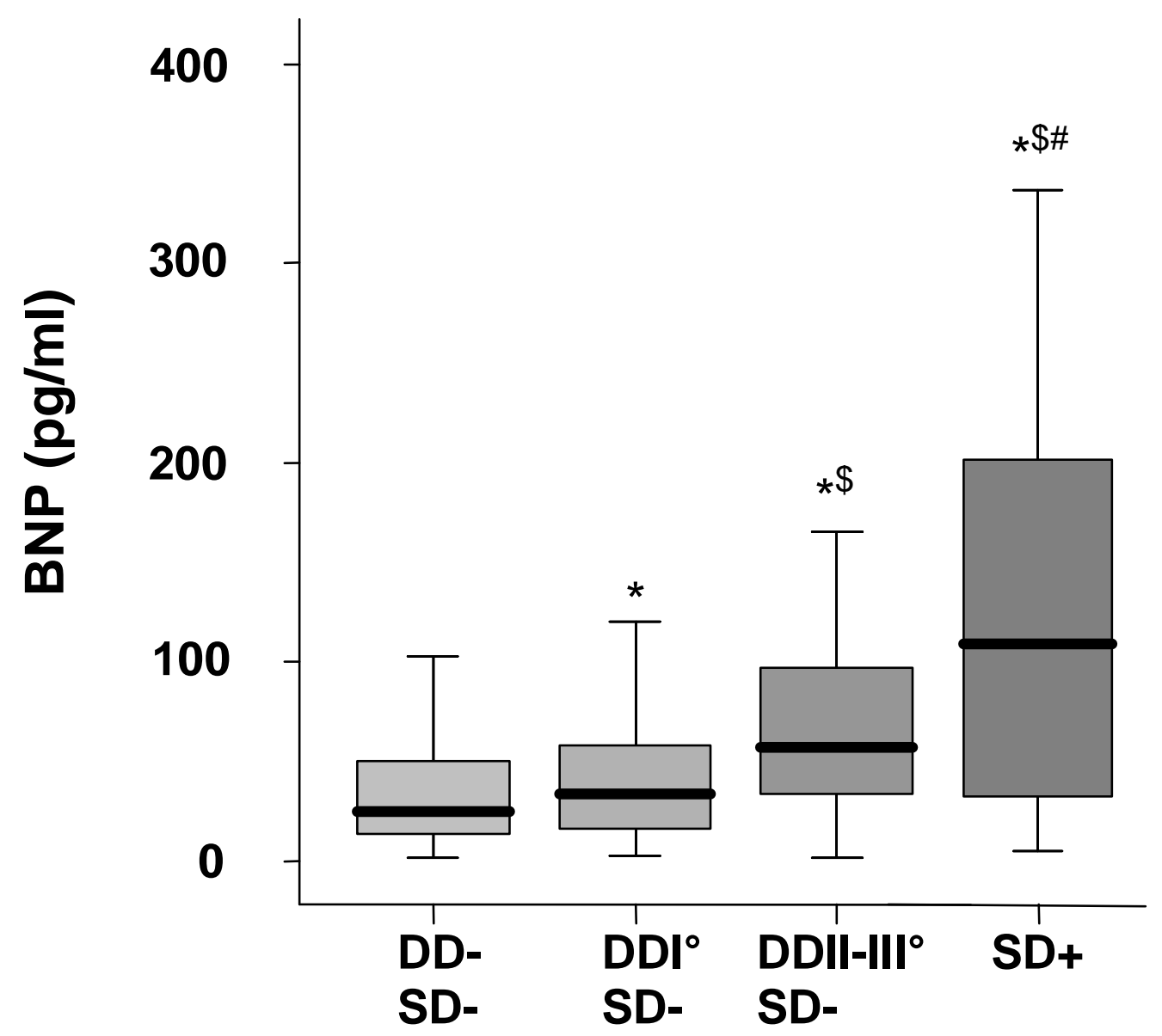

Abbildung 2: $\quad$ Mediane BNP-Plasmakonzentration bei Patienten mit normaler ventrikulärer Funktion (DDSD-), milder $\left(\mathrm{DDI}^{\circ}\right)$, moderater/schwerer diastolischer Dysfunktion (DDII-III $\left.{ }^{\circ}\right)$ und systolischer Dysfunktion (SD+). *p<0,05 vs. normaler linksventrikulärer Funktion. $\$ \mathrm{p}<0,001$ vs. milder diastolischer Dysfunktion. $\# \mathrm{p}<0,05$ vs. moderater/schwerer diastolischer Fehlfunktion. 


\subsection{NT-proBNP-Plasmakonzentration bei Patienten mit normaler linksventrikulärer Funktion}

Der mediane NT-proBNP-Wert lag in dieser Studie bei 115 pg/ml (54-227 pg/ml). Die Referenzbereiche von NT-proBNP liegen für Männer <50 Jahre bei $84 \mathrm{pg} / \mathrm{ml}$, bei Männern >50 Jahre bei 194 pg/ml. Bei Frauen <50 Jahre bei 155 pg/ml und bei >50 Jahren bei 222 $\mathrm{pg} / \mathrm{ml}$. Die funktionale Sensitivität wird mit $<50 \mathrm{pg} / \mathrm{ml}(<5,9 \mathrm{pmol} / \mathrm{l})$ angegeben (Roche Diagnostics 2002). Bei Patienten mit normaler linksventrikulärer Funktion lag die NTproBNP-Plasmakonzentration bei 82 [39-156] pg/ml. Patienten mit einer leichten diastolischen Dysfunktion hatten eine NT-proBNP Wert von 119 [55-218] pg/ml, bei einer moderaten/schweren diastolischen Dysfunktion ergab sich ein Wert von 177 [99-364] pg/ml ( $\mathrm{p}<0,001$ vs. normal und milder diastolischer Dysfunktion) und bei Patienten mit einer systolischen Dysfunktion lag die Plasmakonzentration bei 678 [210-1064] pg/ml (p<0,001 vs. normal vs. milder und moderater/schwerer diastolischer Dysfunktion).

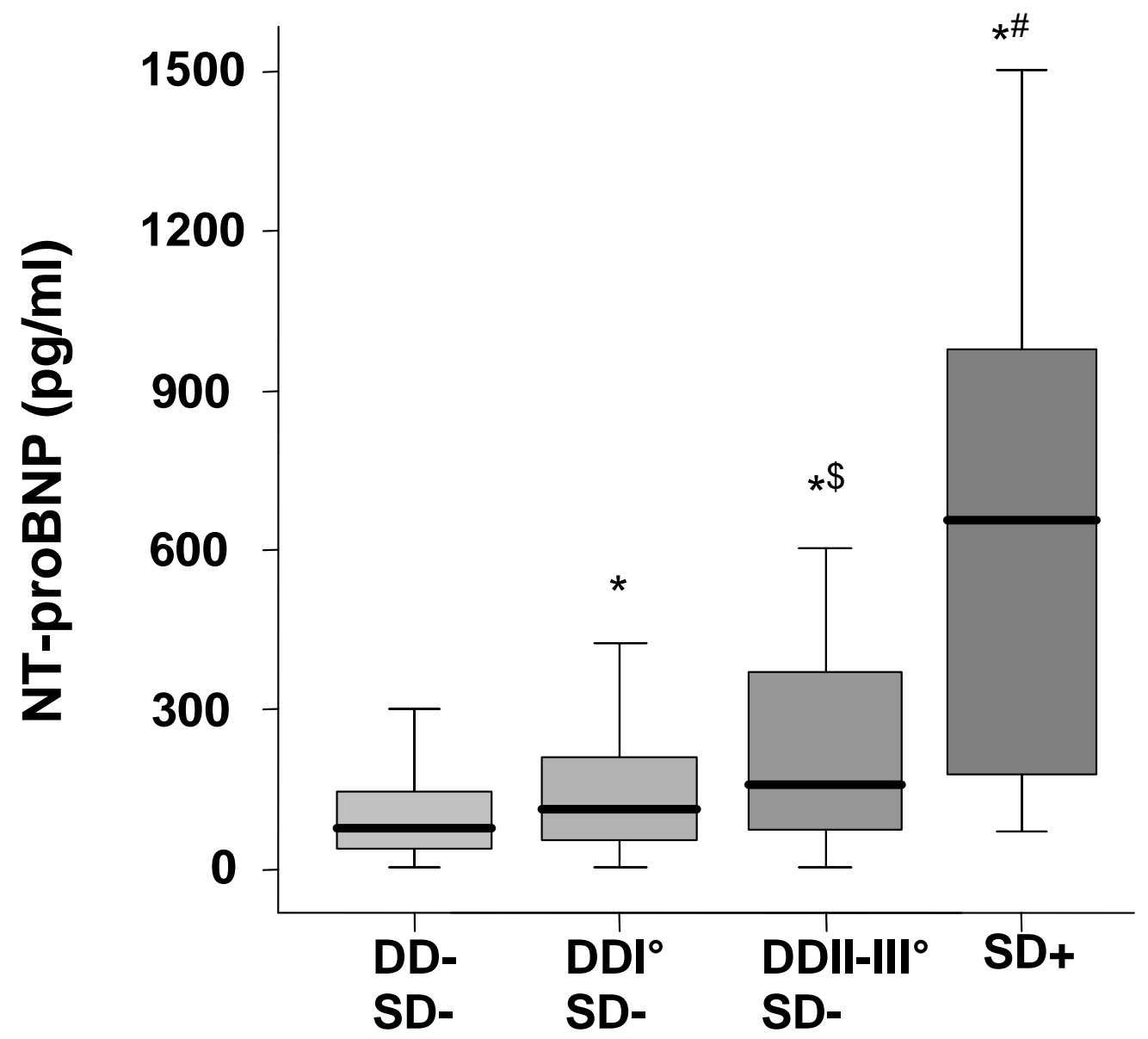

Abbildung 3: Mediane NT-proBNP-Plasmakonzentration bei Patienten mit normaler ventrikulärer Funktion (DD- DS-), milder $\left(\mathrm{DDI}^{\circ}\right)$, mäßig/schwerer diastolischer Dysfunktion (DDII-III ${ }^{\circ}$ ) und systolischer Dysfunktion ( $\mathrm{SD}+)$. ${ }^{*} \mathrm{p}<0,001$ vs. normaler linksventrikulärer Funktion. $\$ \mathrm{p}<0,001$ vs. milder diastolischer Dysfunktion. \#p<0,05 vs. mäßig/schwerer diastolischer Dysfunktion. 


\subsection{Natriuretische Peptide als Prädikator einer linksventrikulären Funktionsstörung}

Die Konzentration der natriuretischen Peptide im Blutplasma war bei den Studienteilnehmern mit einer normalen EF $(\geq 50 \%)$ und normaler diastolischer Funktion am niedrigsten, wohingegen die Plasmakonzentration der Peptide mit der Schwere der linksventrikulären Dysfunktion zunahm (Abbildung 4 und 5). Mit der Zunahme des Grades der diastolischen Dysfunktion konnte ein signifikanter Anstieg der Plasmakonzentration der natriuretischen Peptide beobachtet werden $(\mathrm{p}<0,01)$.

Die Verteilung von lnNT-proANP, lnNT-proBNP und lnBNP in Bezug zur Ejektionsfraktion ist in der Abbildung 4 dargestellt. Hier kann eine Korrelation von lnNT-proANP, lnBNP und lnNT-proBNP mit der Schwere der systolischen Dysfunktion beobachtet werden $(r=0,156$; $0,222 ; 0,260 ; \mathrm{p}<0,001)$.

$\operatorname{lnNT}$-proANP (pg/ml)

$\operatorname{lnNT}-p r o B N P(p g / m l)$

$\operatorname{lnBNP}(\mathbf{p g} / \mathrm{ml})$
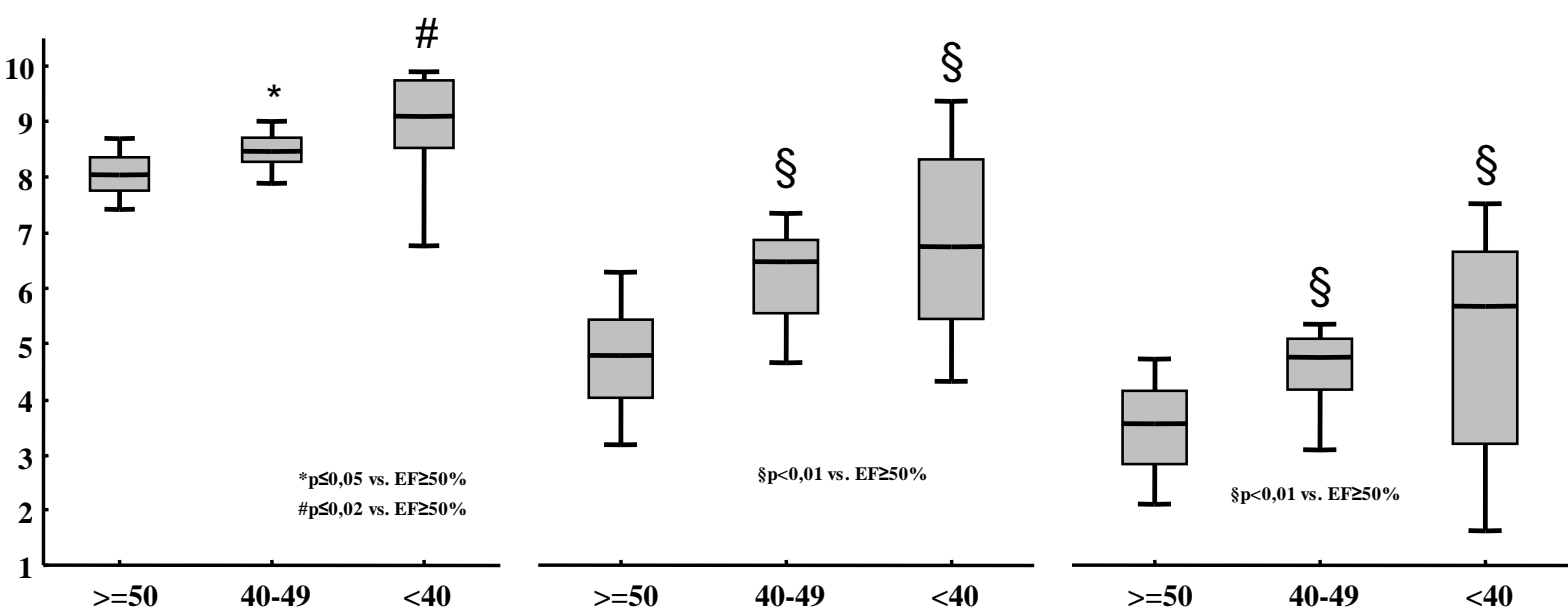

Ejektionsfraktion (\%)

Abbildung 4: Natriuretische Peptide und systolische Funktion. Konzentrationen (Ordinate) von lnNTproANP (links), lnNT-proBNP (Mitte) und lnBNP (rechts). Ventrikuläre systolische Ejektionsfraktion ( $\geq 50 \%$; 40-49\%; $<40 \%$; Abszisse). Box und Whisker Plot: Box durch 25\%und 75\%-Quantil begrenzt, Median als Querbalken, die Whiskers begrenzen das 10\%- und 90\%-Quantil. 
In der Abbildung 5 wird die Verteilung von $\operatorname{lnNT}$-proANP, $\operatorname{lnNT}$-proBNP und $\operatorname{lnBNP}$ in Bezug zum Grad der diastolischen Dysfunktion (und systolischen Dysfunktion zum Vergleich) gezeigt. $\mathrm{Zu}$ sehen ist die Korrelation der diastolischen Dysfunktion ( $\mathrm{r}=0,124$; $\mathrm{p}=0,005$ für NT-proANP; $r=0,249 ; \mathrm{p}<0,001$ für BNP und $\mathrm{r}=0,273, \mathrm{p}<0,001$ für NT-proBNP).

InNT-proANP

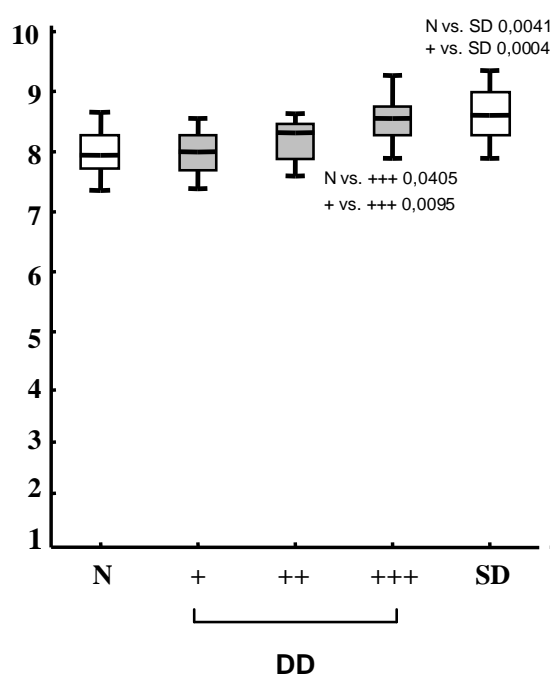

InNT-proBNP

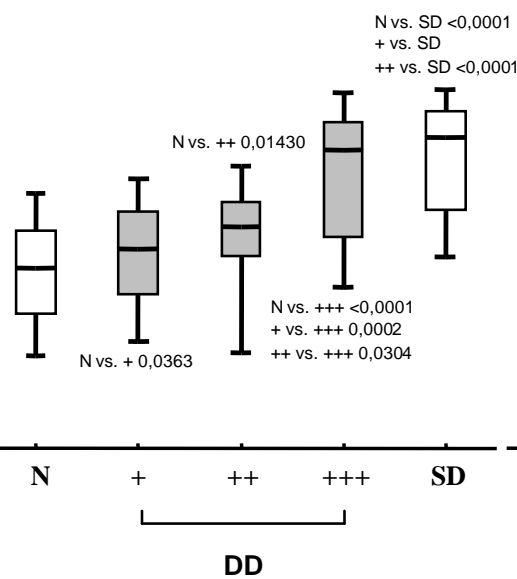

DD

\section{$\operatorname{lnBNP}$}

\footnotetext{
N Normale ventrikuläre Funktion

DD $\left[\begin{array}{cl}+ & \text { Leichte diastolische Dysfunktion } \\ ++ & \text { Moderate diastolische Dysfunktion }\end{array}\right.$

+ + + Diastolische Dysfunktion mit Bewiesenen erhöhten LVEDD

SD Systolische Dysfunktion $(\mathrm{EF}<50 \%)$
}

Abbildung 5: Natriuretische Peptide und diastolische Funktion. Konzentration (Ordinate) von InNT-proANP (links), lnNT-proBNP (Mitte) und lnBNP (rechts) bezogen auf die linksventrikuläre diastolische Funktion (normal (N), leichter (DD+), mäßiger (DD++) oder schwerer (DD+++) diastolischer Dysfunktion; Abszisse). Werte für die systolische Dysfunktion (SD; EF <50\%) wurden zur Verdeutlichung mit aufgeführt. Box und Whisker Plot: Box durch 25\%- und 75\%Quantil begrenzt, Median als Querbalken, die Whiskers begrenzen das 10\%- und 90\%-Quantil.

Da vor allem bei höheren Graden der diastolischen Dysfunktion die linksatriale Entleerung sowie den Anstieg der linksatrialen Wandspannung beeinträchtigt ist, kann hypothesiert werden, dass das Verhältnis von NT-proANP (welches überwiegend aus dem Atrien freigegeben wird) und NT-proBNP (welches hauptsächlich aus dem Ventrikel sezerniert wird) ein besserer diagnostischer Parameter zum Erkennung einer diastolischen Dysfunktion ist als ein Peptid allein. Das NT-proBNP/NT-proANP-Verhältnis war bei Patienten, bei denen eine 
schwere diastolische Dysfunktion und systolische Dysfunktion ( $\mathrm{p}<0,0001$ vs. normaler Funktion) vorlag, am höchsten.

Die Beziehung zwischen der ventrikulären Funktion und den NT-proBNP/NT-proANPQuotienten wird in Abbildung 6 (links) gezeigt. Das NT-proBNP/NT-proANP-Verhältnis nimmt mit der Schwere der diastolischen Dysfunktion zu und war bei Patienten mit schwerer diastolischer und systolischer Dysfunktion am höchsten.

\section{Verhältnis InNT-proBNP/InNT-proANP}
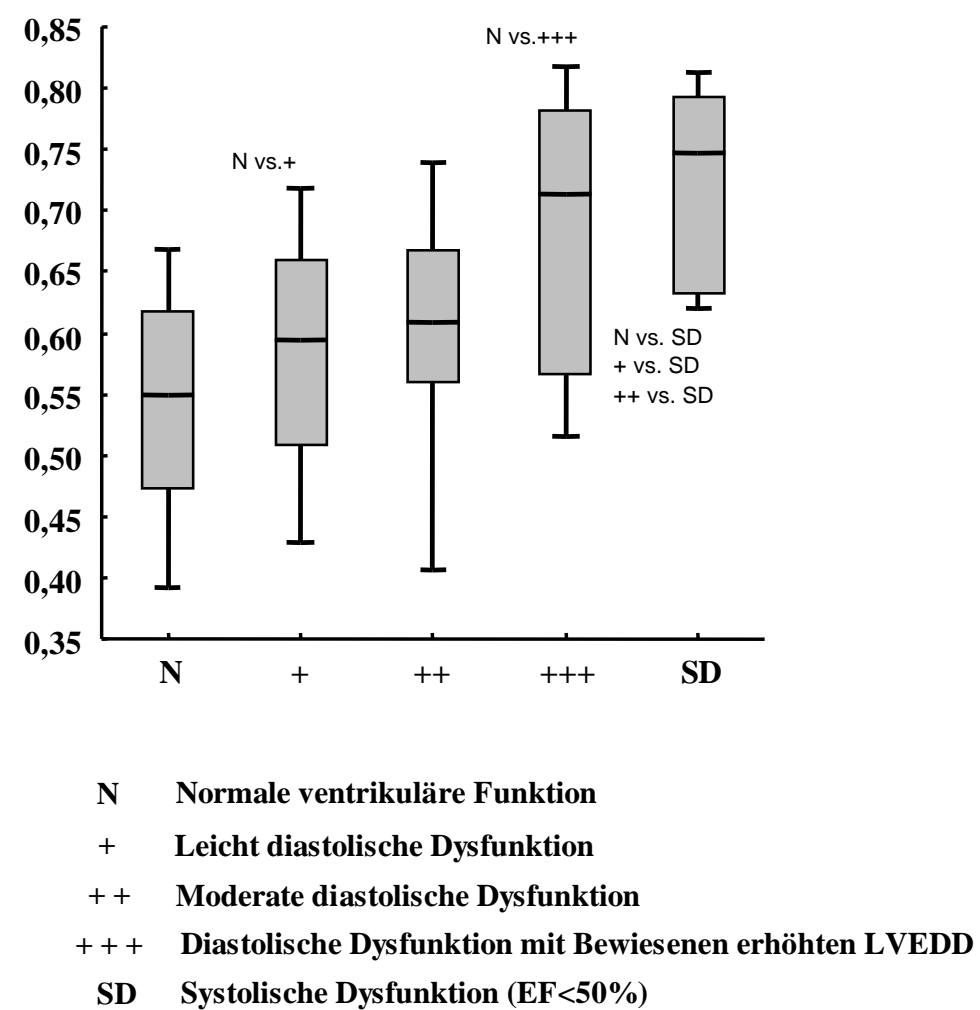

Abbildung 6: Verhältnis von lnNT-proBNP/lnNT-proANP in Bezug zur linksventrikulären Funktion (normal $(\mathrm{N})$, leichter (+), mäßiger (++) oder schwerer (+++) diastolischer Dysfunktion. Systolische Dysfunktion (SD; EF<50\%). Box und Whisker Plot: Box durch 25\%- und 75\%-Quantil begrenzt, Median als Querbalken, die Whiskers begrenzen das 10\%- und 90\%-Quantil. 
3.6 Analyse der ROC-Kurven für eine präklinische ventrikuläre Dysfunktion

Die ROC-Ergebnisse von NT-proANP, NT-proBNP, BNP und das Verhältnis von NTproBNP/NT-proANP zur Diagnosestellung einer präklinischen linksventrikulären Dysfunktion sind in Abbildung 7 sowie in Tabelle 4 dargestellt.

Systolische Dysfunktion

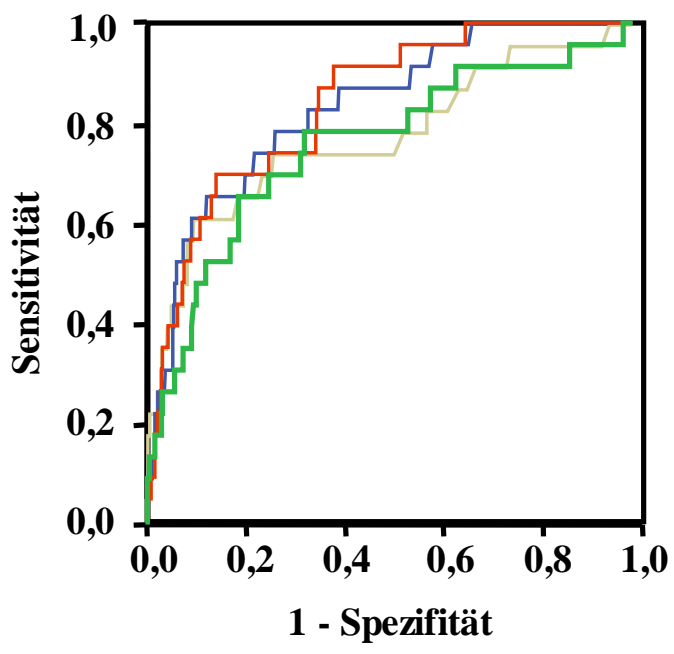

Schwere diastolische Dysfunktion

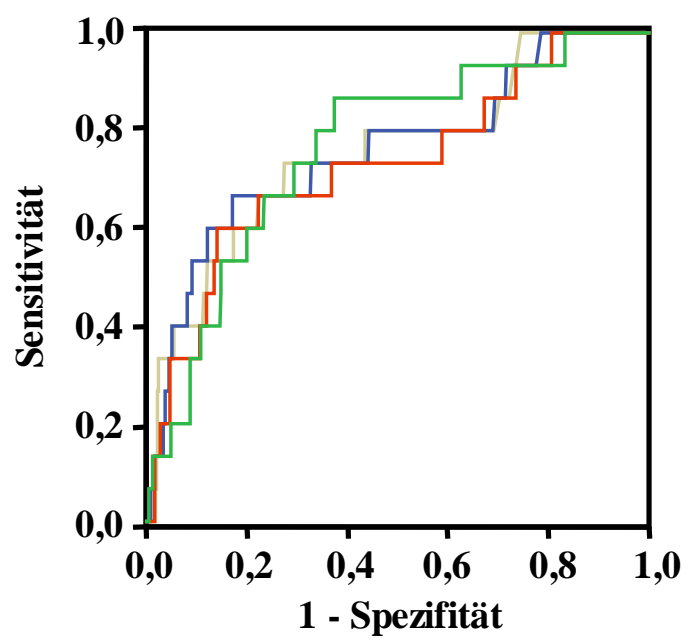

Systolische oder schwere diastolische Dysfunktion

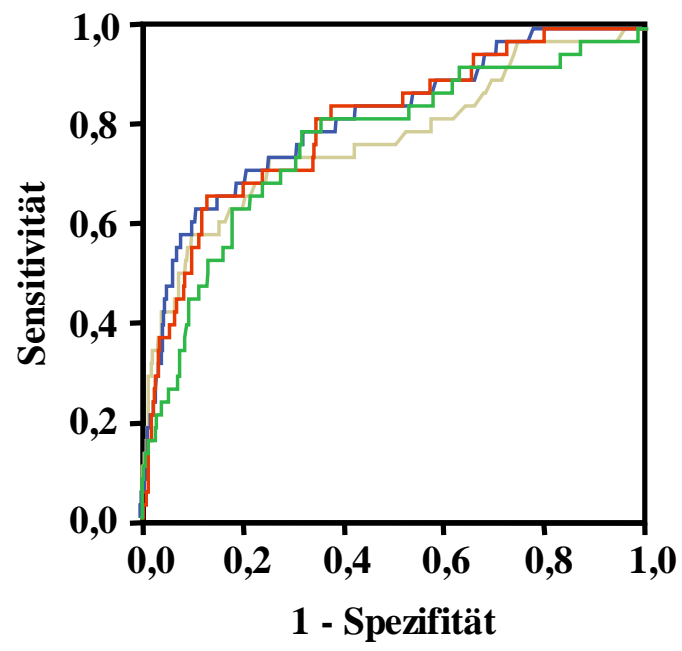

Allgemeine diastolische Dysfunktion

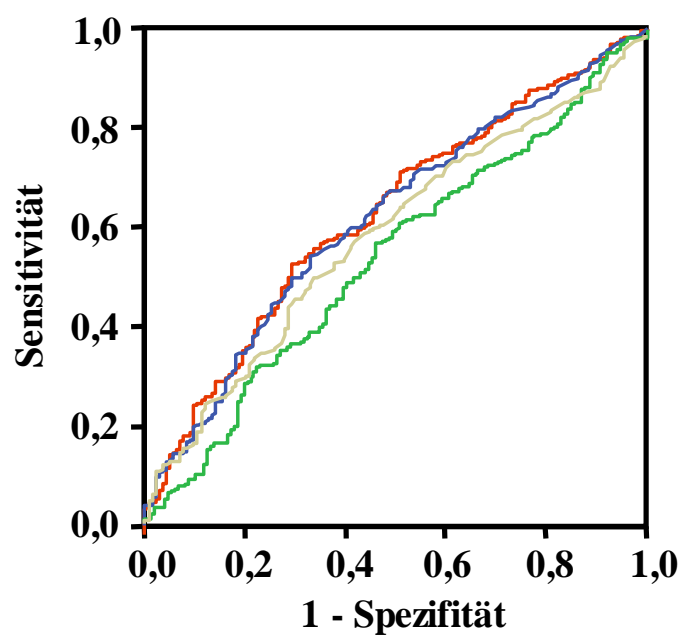

\section{- InNT-proBNP InNT-proANP InBNP InNTproBNP/ InNT-proANP}

Abbildung 7: ROC-Kurven der natriuretischen Peptide für die Diagnose einer systolischen (oben links), schwerer diastolischer (unten links) und systolischer oder diastolischer Dysfunktion (oben rechts). 


\section{Systolische Dysfunktion}

\begin{tabular}{ccccccc}
\hline Variable & AUC [KI] & Cut-off & Sensitivität & Spezifität & $\begin{array}{c}\text { negativer } \\
\text { prädiktiver } \\
\text { Wert }\end{array}$ & $\begin{array}{c}\text { positiver } \\
\text { prädiktiver } \\
\text { Wert }\end{array}$ \\
\hline $\begin{array}{c}\text { InNT-proANP } \\
\text { (pg/ml) }\end{array}$ & $0,751[0,636-0,866]$ & $\begin{array}{c}8,45 \\
(4675,07)\end{array}$ & 65 & 81 & 98 & 13 \\
$\begin{array}{c}\text { InNT-proBNP } \\
\text { (pg/ml) }\end{array}$ & $0,831[0,748-0,914]$ & $\begin{array}{c}5,94 \\
(379,93)\end{array}$ & 65 & 88 & 98 & 19 \\
InBNP (pg/ml) & $0,769[0,651-0,886]$ & $\begin{array}{c}4,65 \\
(104,59)\end{array}$ & 61 & 90 & 98 & 22 \\
InNT-proBNP/ & $0,835[0,759-0,910]$ & 0,70 & 70 & 86 & 98 & 18 \\
InNT-proANP & $0,692[0,594-0,791]$ & 67 & 65 & 66 & 98 & 8 \\
Alter & $0,578[0,440-0,716]$ & 92,75 & 52 & 75 & 97 & 9 \\
GFR & $0,883[0,828-0,938]$ & 8,13 & 91 & 71 & 99 & 12 \\
Score & & & & & \\
\hline
\end{tabular}

Tabelle 4.1: ROC-Analysen bei systolischer Dysfunktion

\section{Systolische oder schwere diastolische Dysfunktion}

\begin{tabular}{|c|c|c|c|c|c|c|}
\hline Variable & $\mathrm{AUC}[\mathrm{KI}]$ & Cut-off & Sensitivität & Spezifität & $\begin{array}{c}\text { negativer } \\
\text { prädiktiver } \\
\text { Wert }\end{array}$ & $\begin{array}{l}\text { positiver } \\
\text { prädiktiver } \\
\text { Wert }\end{array}$ \\
\hline $\begin{array}{l}\text { LnNT-proANP } \\
(\mathrm{pg} / \mathrm{ml})\end{array}$ & $0,765[0,681-0,849]$ & $\begin{array}{c}8,25 \\
(3827,63)\end{array}$ & 79 & 68 & 98 & 16 \\
\hline $\begin{array}{l}\text { LnNT-proBNP } \\
\quad(p g / m l)\end{array}$ & $0,813[0,738-0,888]$ & $\begin{array}{c}5,94 \\
(379,93)\end{array}$ & 63 & 89 & 97 & 30 \\
\hline LnBNP (pg/ml) & $0,772[0,683-0,862]$ & $4,06(57,97)$ & 74 & 75 & 97 & 18 \\
\hline $\begin{array}{l}\text { InNT-proBNP/ } \\
\text { InNT-proANP }\end{array}$ & $0,803[0,729-0,877]$ & 0,70 & 66 & 87 & 97 & 27 \\
\hline Alter & $0,712[0,633-0,792]$ & 69 & 61 & 74 & 96 & 15 \\
\hline GFR & $0,637[0,535-0,738]$ & 92,75 & 58 & 76 & 96 & 16 \\
\hline Score & $0,882[0,831-0,932]$ & 8,13 & 90 & 72 & 99 & 20 \\
\hline
\end{tabular}

Tabelle 4.2: ROC-Ergebnisse bei systolischer oder schwerer diastolischer Dysfunktion 
Schwere diastolische Dysfunktion

\begin{tabular}{|c|c|c|c|c|c|c|}
\hline Variable & $\mathrm{AUC}[\mathrm{KI}]$ & Cut-off & Sensitivität & Spezifität & $\begin{array}{c}\text { negativer } \\
\text { prädiktiver } \\
\text { Wert }\end{array}$ & $\begin{array}{l}\text { positiver } \\
\text { prädiktiver } \\
\text { Wert }\end{array}$ \\
\hline $\begin{array}{l}\text { LnNT-proANP } \\
(p g / m l)\end{array}$ & $0,762[0,647-0,878]$ & $\begin{array}{c}8,19 \\
(3604,72)\end{array}$ & 87 & 63 & 99 & 6 \\
\hline $\begin{array}{l}\text { LnNT-proBNP } \\
\text { (pg/ml) }\end{array}$ & $0,758[0,620-0,895]$ & $\begin{array}{c}5,67 \\
(290,03)\end{array}$ & 67 & 83 & 99 & 10 \\
\hline LnBNP (pg/ml) & $0,754[0,620-0,889]$ & $4,06(57,97)$ & 73 & 72 & 99 & 5 \\
\hline $\begin{array}{l}\text { InNT-proBNP/ } \\
\text { InNT-proANP }\end{array}$ & $0,729[0,588-0,870]$ & 0,71 & 60 & 86 & 98 & 11 \\
\hline Alter & $0,724[0,596-0,852]$ & 69 & 67 & 73 & 99 & 6 \\
\hline GFR & $0,713[0,581-0,844]$ & 93,10 & 67 & 76 & 99 & 7 \\
\hline Score & $0,881[0,803-0,960]$ & 8,13 & 90 & 73 & 99 & 11 \\
\hline
\end{tabular}

Tabelle 4.3: ROC-Ergebnisse bei schwerer diastolischer Dysfunktion

\section{Allgemeine diastolische Dysfunktion}

\begin{tabular}{|c|c|c|c|c|c|c|}
\hline Variable & $\mathrm{AUC}[\mathrm{KI}]$ & Cut-off & Sensitivität & Spezifität & $\begin{array}{c}\text { negativer } \\
\text { prädiktiver } \\
\text { Wert }\end{array}$ & $\begin{array}{l}\text { positiver } \\
\text { prädiktiver } \\
\text { Wert }\end{array}$ \\
\hline $\begin{array}{l}\text { LnNT-proANP } \\
(\mathrm{pg} / \mathrm{ml})\end{array}$ & $0,540[0,488-0,592]$ & $\begin{array}{c}7,51 \\
(1826,21)\end{array}$ & 91 & 21 & 56 & 68 \\
\hline $\begin{array}{l}\text { LnNT-proBNP } \\
(p g / m l)\end{array}$ & $0,514[0,461-0,567]$ & $3,04(20,91)$ & 95 & 15 & 62 & 67 \\
\hline LnBNP (pg/ml) & $0,507[0,455-0,560]$ & $2,40(11,02)$ & 88 & 19 & 47 & 67 \\
\hline $\begin{array}{l}\text { LnNT-proBNP/ } \\
\text { InNT-proANP }\end{array}$ & $0,528[0,475-0,581]$ & 0,54 & 70 & 40 & 42 & 69 \\
\hline Alter & $0,614[0,562-0,665]$ & 57 & 79 & 42 & 52 & 72 \\
\hline GFR & $0,572[0,520-0,624]$ & 70,16 & 80 & 35 & 49 & 70 \\
\hline Score & $0,620[0,577-0,662]$ & 6,73 & 68 & 52 & 43 & 75 \\
\hline
\end{tabular}

Tabelle 4.4: ROC-Ergebnisse bei allgemeiner diastolischer Dysfunktion 
Zur Diagnosestellung einer präklinischen systolischen Dysfunktion (Abbildung 7, oben links), waren die Analysen für alle drei natriuretischen Peptide gut, wobei sich die ROC-Kurven nicht signifikant voneinander unterschieden. Des Weiteren zeigte sich, dass die natriuretischen Peptide sich nicht besonders gut eignen, um eine allgemeine diastolische Dysfunktion zu diagnostizieren (AUC: 0,540 für NT-proANP; 0,507 für BNP und 0,514 für NT-proANP; Abbildung 7 rechts unten; Tabelle 4.4).

Die untere linke Tafel der Abbildung 7 zeigt das Verhaltnen der natriuretischen Peptide für die Diagnose einer schweren diastolischen Dysfunktion. NT-proANP (AUC 0,762), NTproBNP (AUC 0,758) und BNP (AUC 0,754) hatten allesamt nahezu identische Testeigenschaften.

Zusätzlich wurde auch die diagnostische Genauigkeit der natriuretischen Peptide zur Diagnosestellung einer schweren ventrikulären Dysfunktion (EF <50\% oder schwere diastolische Dysfunktion) analysiert. Abbildung 7 (oben rechts) und Tabelle 4 zeigen, dass alle natriuretischen Peptide gute Leistungsmerkmale aufweisen. Beim direkten Vergleich der natriuretischen Peptide zeigte sich, dass die diagnostische Wertigkeit von NT-proBNP für die Diagnosestellung einer ventrikulären Dysfunktion am besten ist.

Weiterhin wurden die prädiktiven Werte der geschätzten GFR und dem Alter zum Erkennen von Patienten, die ein Risiko für eine präklinische ventrikuläre Dysfunktion haben, analysiert (Tabelle 4). Hierbei war NT-proBNP für die Vorhersage einer schweren diastolischen oder systolischen Dysfunktion, verglichen zum Alter oder der GFR, signifikant überlegen. Zur Identifikation von Patienten mit einer allgemeinen diastolischer Dysfunktion ( $\mathrm{p}=0.001)$ zeigte das Alter jedoch eine deutlichere Signifikanz als NT-proBNP.

\subsection{Univariate und multivariate Regressionsanalyse für eine präklinische ventrikuläre Dysfunktion}

Um die Identifikation von Patienten mit einer präklinischen ventrikulären Dysfunktion zu optimieren, wurde eine univariate und eine multivariate Regressionsanalyse mit folgenden Variablen durchgeführt: lnNT-proBNP, Alter, Hypertonus, Diabetes, KHK, Dyspnoe bei Belastung. Wenn für $\mathrm{p}<0,05$ galt wurden die Variablen mit einbezogen, war $\mathrm{p}<0,10$ wurden diese nicht mit in Betracht gezogen. Die Ergebnisse hierzu werden in Tabelle 5 aufgeführt. 


\section{Multivariate Regression - Systolische Dysfunktion}

Odds Ratio

$\mathrm{p}$

(95\% Konfidenzintervall)

LnNT-proBNP [pg/ml]

$2,966(1,960-4,490)$

$<0,001$

Dyspnoe bei Belastung

$4,186(1,537-11,400)$

0,005

Tabelle 5.1: Multivariate Regression bei systolischer Dysfunktion

Multivariate Regression - Systolische oder schwere diastolische Dysfunktion

Odds Ratio

(95\% Konfidenzintervall)

LnNT-proBNP [pg/ml]

Diabetes

Dyspnoe bei Belastung

Hypertonus

KHK
$2,726(1,882-3,949)$

$2,869(1,312-6,272)$

$3,317(1,478-7,443)$

$6,581(0,847-51,127)$

$2,639(1,212-5,746)$ $\mathrm{p}$

$<0,001$

0,008

0,004

0,072

0,015

Tabelle 5.2: Multivariate Regression bei systolischer oder schwerer diastolischer Dysfunktion 


\section{Multivariate Regression - Schwere diastolische Dysfunktion}

Odds Ratio

(95\% Konfidenzintervall)

LnNT-proBNP [pg/ml]

Diabetes

Dyspnoe bei Belastung

Hypertonus

KHK
$2,611(1,807-3,771)$

$3,004(1,371-6,581)$

$3,744(1,637-8,564)$

$6,342(0,817-49,244)$

$2,475(1,130-5,420)$ $\mathrm{p}$

$<0,001$

0,006

0,002

0,077

0,026

Tabelle 5.3: Multivariate Regression bei schwerer diastolischer Dysfunktion

\section{Multivariate Regression - Allgemeine diastolische Dysfunktion}

Odds Ratio

(95\% Konfidenzintervall)

Alter [Jahre] $\mathrm{p}$

$<0,001$

Tabelle 5.4: Multivariate Regression bei allgemeiner diastolischer Dysfunktion 
LnNT-proBNP (O.R. 2,966; p<0,001) und Dyspnoe bei Belastung (O.R. 4,186; p=0,005) waren unabhängig mit der systolischen Dysfunktion assoziiert.

Für die systolische oder schwere diastolische Dysfunktion waren lnNT-proBNP (O.R. 2,726; p<0,001), Hypertonus (O.R. 6,581; p=0,072), Diabetes (O.R. 2,869; p=0,008), KHK (O.R. 2,639; $\mathrm{p}=0,015$ ) und Dyspnoe bei Belastung (O.R. 3,317; p=0,004) unabhängige Prädikatoren.

LnNT-proBNP (O.R. 2,611; p<0,001), Diabetes (O.R. 3,004; p=0,006), Dyspnoe bei Belastung (O.R. 3,744; p=0,002, Hypertonus (O.R. 6,342; p=0,077) und KHK (O.R. 2,475; $\mathrm{p}=0,026$ ) waren unabhängige Prädikatoren der schweren präklinischen diastolischen Dysfunktion.

Von allen getesteten Parametern, war nur das Alter (O.R. 1,069; $p<0,001)$ ein unabhängiger Prädikator für die Präsenz der allgemeinen diastolischen Dysfunktion.

Mit Hilfe der Regressionskoeffizenten der multivariaten Regressionsanalyse wurde ein ScoreSystem entwickelt, welches die klinischen Variablen mit den besten Charakteristika zur Vorhersage für eine asymptomatische linksventrikuläre Dysfunktion einbezieht. Dieser Score wurde wie folgt errechnet:

Score $_{\text {ventrikuläre Dysfunktion }}=1,054$ x Diabetes $+1,884$ x Hypertonus $+1,199 \times$ Dyspnoe bei Belastung $+0,970 \times \mathrm{KHK}+1,003 \times \operatorname{lnNT}$-proBNP. 
Als nächstes wurde die diagnostische Genauigkeit des Scores im Vergleich zum alleinigen lnNT-proBNP durch die ROC Analyse getestet.

Systolische Dysfunktion

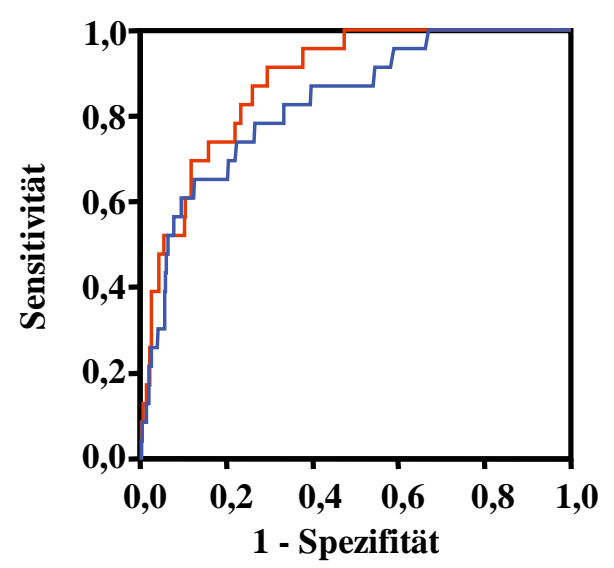

Schwere diastolische Dysfunktion

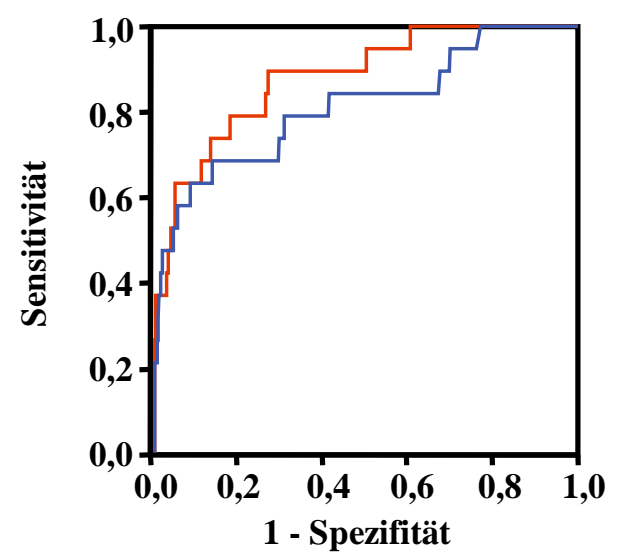

Systolische oder schwere diastolische Dysfunktion

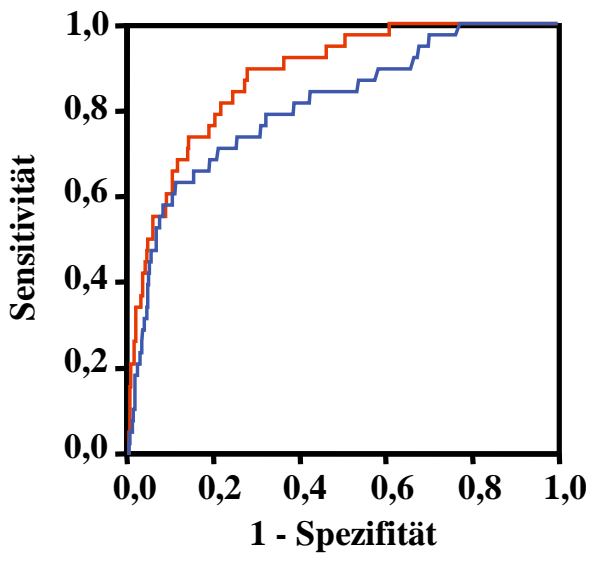

Allgemeine diastolische Dysfunktion

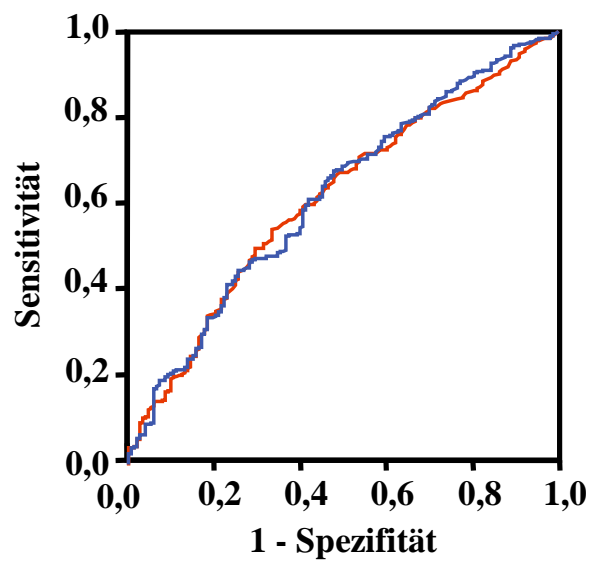

\section{- Score \\ - InNT-proBNP}

Abbildung 8: ROC-Kurven des Score-Models für die Diagnose jeder systolischen (EF>50\%; oben links), allgemeine diastolischen (unten rechts), schwerer diastolischer (unten links) und systolischer oder schwerer diastolischer (oben rechts) Dysfunktion. Die ROC-Analyse für lnNT-proBNP allein ist zum Vergleich mit aufgeführt. 
NT-proBNP wurde in weiteren Analysen eingesetzt, da es das natriuretische Peptid mit der größten diagnostischen Genauigkeit in dieser Patientenkohorte ist. Es wurde offensichtlich, dass ein einfacher klinischer Score, welcher klinische Parameter mit lnNT-proBNP verbindet, eine höhere Genauigkeit zur Diagnosestellung einer schweren diastolischen oder systolischen ventrikulären Dysfunktion ( $\mathrm{p}=0,02)$ aufweist, als $\operatorname{lnNT}$-proBNP allein.

Mit Hilfe der Leave-One-Out-Kreuzvalidierung ergab sich ein Prozentsatz von korrekt klassifizierten Fällen von 95\% für die systolische Dysfunktion, 93\% für die systolische oder schwere diastolische Dysfunktion und 96\% für schwere diastolische Dysfunktion, jedoch nur $35 \%$ für eine allgemeine diastolische Dysfunktion. 


\subsection{Optimierung des Screening-Modells bei einer asymptomatischen linksventrikulären Dysfunktion}

Es wurden unterschiedliche mögliche Screnning-Strategien zum Aufdecken einer schweren ventrikulären Dysfunktion verglichen (z.B. EF $<50 \%$ und/oder schwere diastolische Dysfunktion; Tabelle 6).

\begin{tabular}{|c|c|c|c|c|c|c|c|c|c|}
\hline & Modelle & $\begin{array}{c}\text { Sensitivität } \\
(\%)\end{array}$ & $\begin{array}{l}\text { Spezifität } \\
(\%)\end{array}$ & $\mathbf{W V +}$ & WV- & $\begin{array}{c}\text { Bedarf } \\
\text { NT- } \\
\text { proBNP } \\
(\%)\end{array}$ & $\begin{array}{c}\text { Bedarf } \\
\text { Echo } \\
(\%)\end{array}$ & $\begin{array}{c}\text { Nicht- } \\
\text { erfasste } \\
\text { Kranke } \\
(\%)\end{array}$ & $\begin{array}{r}\text { Anzah } \\
\text { Echo }\end{array}$ \\
\hline 1 & Echokardiographie bei allen Patienten & 100 & 100 & 1,0 & 0 & 0 & 100 & 0 & 14,3 \\
\hline 2 & NT-proBNP allein, cut-off $209,5 \mathrm{pg} / \mathrm{ml}$ & 74 & 75 & 2,9 & 0,4 & 100 & 29 & 26 & 5,5 \\
\hline 3 & Echo bei allen Patienten mit Hypertonus & 97 & 15 & 1,1 & 0,2 & 0 & 86 & 3 & 12,6 \\
\hline 4 & $\begin{array}{l}\text { Wenn Hypertonus, dann NT-proBNP (cut- } \\
\text { off } 209,5 \mathrm{pg} / \mathrm{ml} \text { ) }\end{array}$ & 71 & 78 & 3,2 & 0,4 & 86 & 26 & 29 & 5,2 \\
\hline 5 & Echo bei allen Patienten mit Diabetes & 47 & 70 & 1,6 & 0,8 & 0 & 31 & 53 & 9,4 \\
\hline 6 & $\begin{array}{l}\text { Wenn Diabetes, dann NT-proBNP (cut-off } \\
209,5 \mathrm{pg} / \mathrm{ml} \text { ) }\end{array}$ & 32 & 95 & 6,6 & 0,7 & 31 & 7 & 68 & 3,0 \\
\hline 7 & Echo bei allen Patienten mit KHK & 63 & 73 & 2,3 & 0,5 & 0 & 30 & 37 & 6,8 \\
\hline 8 & $\begin{array}{l}\text { Wenn KHK, dann NT-proBNP (cut-off } \\
209,5 \mathrm{pg} / \mathrm{ml} \text { ) }\end{array}$ & 47 & 88 & 4,1 & 0,6 & 30 & 14 & 53 & 4,2 \\
\hline 9 & Echo bei allen Patienten mit Dyspnoe & 71 & 67 & 2,2 & 0,4 & 0 & 35 & 29 & 7,1 \\
\hline 10 & $\begin{array}{l}\text { Wenn Dyspnoe, dann NT-proBNP (cut-off } \\
209,5 \mathrm{pg} / \mathrm{ml} \text { ) }\end{array}$ & 53 & 89 & 4,8 & 0,5 & 35 & 14 & 47 & 3,8 \\
\hline 11 & $\begin{array}{l}\text { Echo bei allen Patienten mit Dyspnoe oder } \\
\text { KHK }\end{array}$ & 89 & 53 & 1,9 & 0,2 & 0 & 50 & 11 & 8,0 \\
\hline 12 & $\begin{array}{l}\text { Wenn Dyspnoe oder KHK, dann NT- } \\
\text { proBNP (cut-off } 209,5 \mathrm{pg} / \mathrm{ml} \text { ) }\end{array}$ & 68 & 84 & 4,3 & 0,4 & 50 & 20 & 32 & 4,1 \\
\hline 13 & $\begin{array}{l}\text { Echo bei allen Patienten mit Diabetes, } \\
\text { Dyspnoe oder KHK }\end{array}$ & 95 & 36 & 1,5 & 0,1 & 0 & 67 & 5 & 10,0 \\
\hline 14 & $\begin{array}{l}\text { Wenn Diabetes, Dyspnoe oder KHK, dann } \\
\text { NT-proBNP (cut-off } 209,5 \mathrm{pg} / \mathrm{ml} \text { ) }\end{array}$ & 68 & 83 & 3,9 & 0,4 & 67 & 21 & 32 & 4,4 \\
\hline 15 & Score (cut-off 8,551 ) & 82 & 79 & 3,8 & 0,2 & 100 & 26 & 18 & 4,5 \\
\hline
\end{tabular}

Tabelle 6: Screening-Modelle

Nach Testung der verschiedenen Vorgehensweisen wie in Tabelle 6 aufgeführt, zeigt sich, dass man 14,3 echokardiographische Untersuchungen durchführen muss um einen Patienten mit einer ventrikulären Dysfunktion aufzufinden. Das echokardiographisches Screening von allen Patienten, die ein Risikoprofil aufweisen, hat eine Sensitivität und Spezifität von 100\% sowie eine positives Wahrscheinlichkeits-Verhältnis (WV+) von 1. 
Für NT-proBNP (,cut-off’ 209,5 pg/ml) alleine ergibt sich eine Reduktion der Sensitivität auf 74\% und der Spezifität auf 75\%, wobei sich aber auch die Anzahl der benötigten Echokardiographien zur Identifikation von einem Patienten mit einer ventrikulären Dysfunktion auf 5,5 reduziert. Die effizienteste Strategie zum Aufdecken einer ventrikulären Dysfunktion ist eine Echokardiographie bei Patienten mit Diabetes und ein NT-proBNP-Wert oberhalb des „cut-off level“ von 209,5 pg/ml. Jedoch würde man mit dieser Vorgehensweise nur ein Drittel aller Patienten mit einer schweren ventrikulären Dysfunktion entdecken.

Wird eine klinische Diagnose, welche prädisponierend für eine ventrikuläre Dysfunktion ist, mit NT-proBNP kombiniert, so verringert sich die Anzahl der benötigten echokardiographischen Untersuchungen um die Diagnose zu sichern.

Die Gesamt-Test-Eigenschaften waren für den entwickelten Screening-Score am besten. So ergab dieser Score („cut-off“ gesetzt bei 8,551 Punkten) eine Sensitivität von $82 \%$ und Spezifität von $79 \%$ für eine genaue Diagnose, beziehungsweise die Anzahl der benötigten Echokardiographien zur Identifikation eines betroffenen Patienten war 4,5 bei nur $18 \%$ von fehlenden erkrankten Patienten (Tabelle 6). 
Abbildung 9 zeigt die Überlegenheit des Score-Systems, welches klinische und lnNTproBNP-Werte kombiniert gegenüber NT-proBNP allein bezogen auf die benötigten echokardiographischen Untersuchungen.

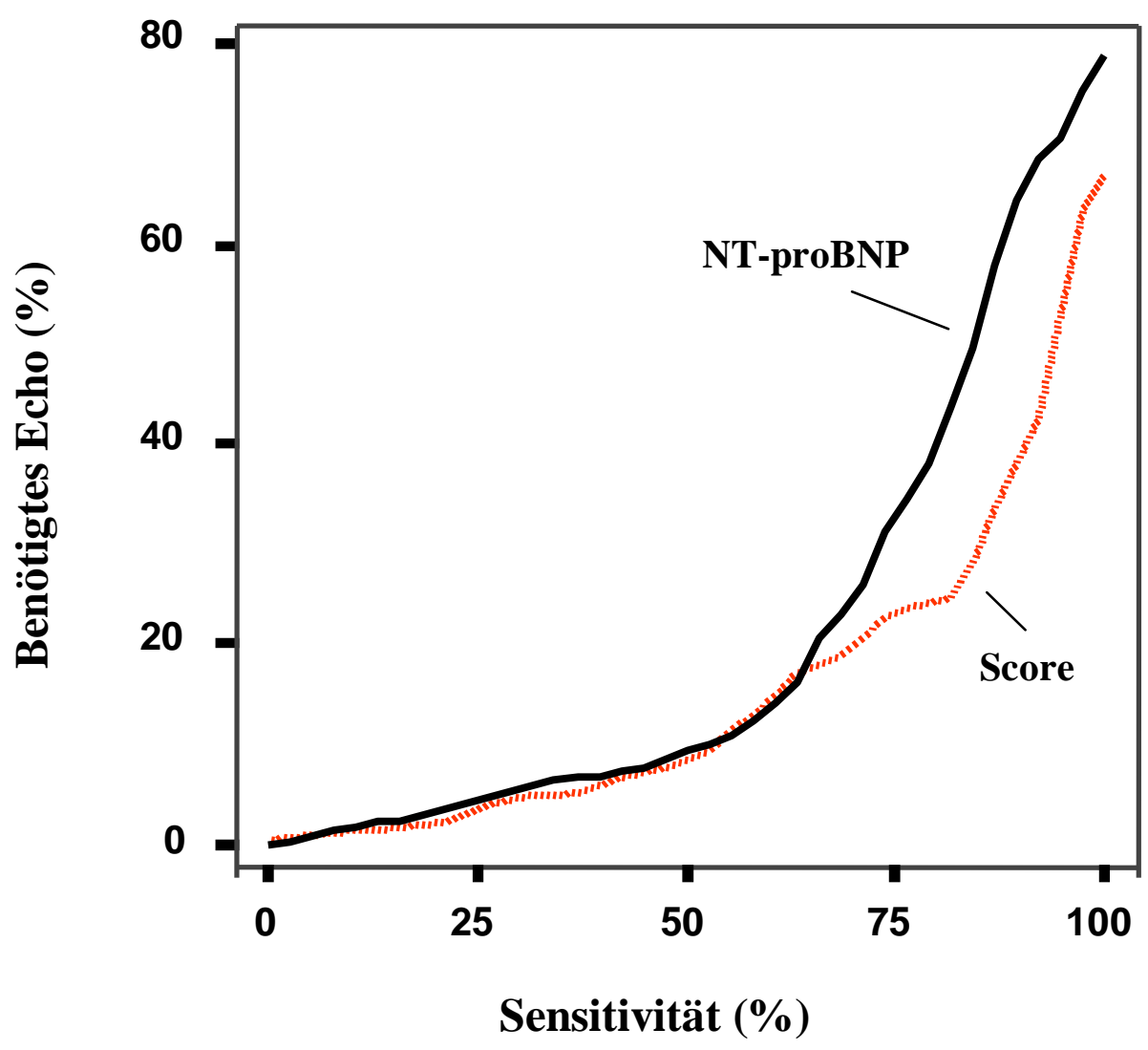

Abbildung 9: Das Score-System verglichen mit NT-proBNP allein zur Identifikation von Patienten mit dem Risiko für eine systolische oder schwere diastolische linksventrikuläre Dysfunktion. Die Anzahl der Patienten, die ein Echokardiogramm benötigen (Abszisse), ist graphisch dargestellt gegenüber der Sensitivität des Test-Produktes.

Mit zunehmender Sensitivität reduziert der Score größtenteils die Anzahl der nötigten Echokardiographien im Vergleich zu NT-proBNP allein. Als Beispiel: Zum Auffinden von mindestens $80 \%$ der betroffenen Patienten würde eine Echokardiographie bei $42 \%$ der Teilnehmer erforderlich sein, wenn die Entscheidung allein auf NT-proBNP basierte. Im Vergleich dazu wären bei nur 26\% eine Echokardiographie notwendig, wenn man den Score benutzte. 


\section{DISKUSSION}

Bei 30-50\% der Patienten, die an Symptomen einer Herzinsuffizienz leiden, zeigt sich eine diastolische Herzinsuffizienz. Die Prävalenz ist deutlich altersabhängig. Auch die systolische Herzinsuffizienz ist speziell im Alter ein häufiges Krankheitsbild, hierbei erreicht die Prävalenz $10 \%$. Beide Formen der Herzinsuffizienz sind in der alltäglichen Diagnostik von hospitalisierten Patienten sehr kostenintensiv (Vasan et al. 1995; Lee et al. 2004).

Folglich müssen neue kosteneffektive Strategien entwickelt werden, um Patienten mit Risiken für die Entwicklung einer Herzinsuffizienz frühzeitig zu erfassen und zu behandeln (Ofman $e t$ al. 2004; Armstrong und Moe 1994).

In Anbetracht der großen Anzahl von Patienten mit einer kardialen Erkrankung, bei denen ein Risiko für die Entwicklung einer linksventrikulären Dysfunktion vermutet wird, ist das Interesse am Einsatz der natriuretischen Peptide für die Differentialdiagnose und als Marker für die Veränderung und Funktion linksventrikulärer Strukturen stetig gewachsen (Davis et al. 1994).

In der ausgewählten Studienpopulation mit Risikofaktoren für eine Herzinsuffizienz hatten $65 \%$ der Teilnehmer eine diastolische Dysfunktion.

In dieser Arbeit wurde die Bedeutung von NT-proANP, NT-proBNP und BNP für die Diagnose einer diastolischen und systolischen Dysfunktion bei Patienten mit Risikofaktoren für die Entwicklung einer Herzinsuffizienz, aber ohne generelle Symptome einer Herzinsuffizienz, untersucht.

Die Ergebnisse zeigen, dass in dieser Studie die natriuretischen Peptide für die Diagnose einer schweren diastolischen oder systolischen Dysfunktion wertvoll sind. Ein Score-System, welches klinische Parameter mit den natriuretischen Peptiden verbindet, verbessert die diagnostische Genauigkeit der Erkennung einer asymptomatischen systolischen oder schweren diastolischen Dysfunktion. 


\subsection{Bedeutung der natriuretischen Peptide für die Diagnose einer ventrikulären Dysfunktion}

In einer anfänglichen Studie wurde BNP bei Patienten im Alter über 55 Jahre als ein Screening-Test gebraucht. Hier ergab sich eine Sensitivität von $92 \%$ und eine Spezifität von 72\% zur Erkennung einer asymptomatischen linksventrikulären systolischen Dysfunktion. Unter dem Strich kann mit dieser und anderen vorausgegangenen Beobachtungen gesagt werden, dass NT-proANP, BNP und NT-proBNP bei Patienten mit einer präklinischen systolischen Dysfunktion im Vergleich zu Patienten mit normaler systolischer Funktion, signifikant erhöht sind (Groenning et al. 2004; Richards 2004).

Eine Studie von Lerman et al. konzentrierte sich auf die Wertigkeit von NT-proANP zur Diagnosestellung einer asymptomatischen linksventrikulären Dysfunktion. Die Autoren fanden einen hohen prädiktiven Wert von NT-proANP für die asymptomatische systolische Dysfunktion sowie für die symptomatische systolische Herzinsuffizienz (Lerman et al. 1993).

Die Aussage der diagnostischen Wertigkeit der natriuretischen Peptide zur Aufdeckung einer diastolischen Dysfunktion und diastolischen Herzinsuffizienz wird kontrovers diskutiert, wobei bisher veröffentlichte Berichte unterschiedliche Ergebnisse zeigen (Lubien et al. 2002; Redfield 2004).

In dieser Studie sollten diese Beobachtungen auf Patienten mit dem Risiko einer Herzinsuffizienz ausgedehnt werden. Es wurde festgestellt, dass die Plasmakonzentration von NT-proBNP und BNP bei einer leichten diastolischen Dysfunktion im Vergleich zur normalen linksventrikulären Funktion signifikant höher ist. Allerdings kann in dieser Arbeit gezeigt werden, dass die natriuretischen Peptide zwar eine leichte oder moderate diastolische Dysfunktion nicht genau vorhersagen können, jedoch ein sehr wertvolles Werkzeug für die Identifikation von Patienten mit einer schweren diastolischen oder systolischen Dysfunktion sind. Die Plasmakonzentrationen von NT-proANP, NT-proBNP und BNP sind bei einer moderaten/schweren diastolischen Dysfunktion im Vergleich zur leichten diastolischen Dysfunktion oder normalen linksventrikulären Funktion signifikant erhöht.

Zwei Hauptpunkte unterscheiden diese Arbeit von bereits veröffentlichten Studien: Lubien et al. analysierte eine Gruppe von hoch selektierten Patienten (Lubien et al. 2002), wohingegen andere einen bevölkerungsbasierenden Durchschnitt gewählt haben (Redfield 2004). Das 
Patientenkollektiv dieser Studie ist zwischen den beiden vorher genannten Gruppen angesiedelt, da es sich um Patienten handelte, die mit kardiovaskulären Risikofaktoren in allgemeinmedizinischer Behandlung waren. Ein effektives Screening auf eine ventrikuläre Dysfunktion in allgemeinmedizinischen Praxen wäre wünschenswert, da es wahrscheinlich den wirtschaftlichen Gebrauch von Überweisungen zu Fachärzten, die Risiko-Stratifizierung und die therapeutische Behandlung verbessern würde.

Ein weiterer Punkt ist die Definition der diastolischen Dysfunktion. Redfield et al. nimmt zwei unabhängige echokardiographische Zeichen der moderaten diastolischen Dysfunktion zum Beweisen der Diagnose (Redfield et al. 2003).

Nach neueren Empfehlungen der European Society of Cardiology wird in dieser Arbeit die schwere diastolische Dysfunktion als ein eingeschränktes Füllungs-Muster (restrictive filling pattern) und/oder Anzeichen eines erhöhten Füllungs-Drucks (linksatrialer Durchmesser >45 mm und E/E’>15) definiert (Paulus et al. 2007).

Eine Zunahme des linksatrialen Durchmessers oder des Volumens als auch ein E/E'>15 ist assoziiert mit einem erhöhten Füllungs-Druck bei Patienten mit einer Herzinsuffizienz und einer normalen Ejektionsfraktion (Nagueh et al. 2004; Poerner et al. 2003). Die Ergebnisse zeigen, dass die natriuretischen Peptide eine wichtige Rolle zum Screening einer schweren diastolischen oder jeder systolischen Dysfunktion in den allgemeinmedizinischen Praxen haben könnten.

\subsection{Vergleich von NT-proANP, NT-proBNP und BNP für die Entdeckung einer präklinischen linksventrikulären Dysfunktion}

Das Studiendesign erlaubt den direkten Vergleich von NT-proANP, NT-proBNP und BNP zur Entdeckung einer systolischen oder diastolischen Dysfunktion durch eine vergleichende ROC-Analyse oder vergleichende Korrelations-Analyse.

So kann in dieser Arbeit aufgezeigt werden, dass die Plasmakonzentrationen von NTproANP, NT-proBNP und BNP bei der systolischen Dysfunktion im Vergleich zur normalen systolischen Funktion und der diastolischen Dysfunktion signifikant erhöht sind. Der Unterschied zwischen NT-proBNP und BNP für die Diagnose einer diastolischen und systolischen Dysfunktion war jedoch statistisch nicht signifikant (Hobbs et al. 2004; Mueller T et al. 2005). 
In der ROC-Analyse konnte festgestellt werden, dass NT-proBNP der beste Marker für die linksventrikuläre systolische Dysfunktion sowie der linksventrikulären diastolischen Dysfunktion, verglichen mit NT-proANP und BNP, ist. Dieses Ergebnis schließt sich den Ergebnissen vorangegangener Studien an, in denen gezeigt wurde, dass das NT-proBNP die systolische Dysfunktion mit symptomatischer/asymptomatischer linksventrikulärer Dysfunktion und nach akutem Myokardinfarkt mit einer höheren Sensitivität aufdecken kann als NT-proANP, BNP, eine klinische Anamnese oder eine körperliche Untersuchung (Olsen et al. 2004; Choy et al. 1994; Motwani et al. 1993).

So unterstützt diese Arbeit die Ergebnisse, welche zeigen, dass das Messen der natriuretischen Peptide im speziellen NT-proBNP hilfreich für das Screenen von Patienten mit Risikofaktoren, auf das Vorliegen eine asymptomatische linksventrikuläre systolische Dysfunktion, sein kann (McDonagh et al. 2004; Hall et al. 2003).

Die NT-proBNP-Plasmakonzentrationen waren in dieser Studie, verglichen mit denen von NT-proANP, zum Auffinden jeder systolischen oder diastolischen Dysfunktion überlegen.

Interessanterweise ist das NT-proANP das einzige natriuretische Peptid, welches von einer leichten diastolischen Dysfunktion nicht beeinflusst wird, jedoch bei einer moderaten/schweren diastolischen Dysfunktion ansteigt. Die Veränderung von einer leichten diastolischen Dysfunktion zu einer moderaten/schweren diastolischen Dysfunktion wird charakterisiert durch die Pseudonormalisierung des mitralen Flussprofils, welches aus einer Erhöhung der Vorlast und Zunahme der linksatrialen Wandspannung resultiert. Die NTproANP-Konzentration im Plasma hängt im wesentlich mit der atrialen Wandspannung zusammen. Bei der Beeinträchtigung der Relaxation nimmt diese zu. Da jedoch bei einer leichten diastolischen Dysfunktion, der linksatriale Druck für gewöhnlich normal oder leicht niedriger ist, kommt es nicht zu einer wesentlichen Erhöhung von NT-proANP. Im Gegensatz dazu erhöht sich die NT-proANP-Plasmakonzentration bei der moderaten/schweren diastolischen Dysfunktion, da es hier zu einer deutlichen Zunahme der atrialen Wandspannung kommt.

Überdies gibt es neben der atrialen, eine ventrikuläre Sekretion von NT-proANP (Nakagawa et al. 1995). So kann unter Berücksichtigung dieser Feststellung angenommen werden, dass im Falle der Pseudonormalisierung, bei der die ventrikuläre Wandspannung zunimmt, es neben der NT-proBNP-Sekretion zu einem Anstieg der Freisetzung von NT-proANP aus den 
Ventrikeln kommt. Bei der Zunahme der diastolischen Dysfunktion vom Stadium der verzögerten Relaxation zur Pseudonormalisation kommt es also zu einem Anstieg der NTproANP- und NT-proBNP-Plasmakonzentration.

Obwohl die natriuretischen Peptide für den Gebrauch der Diagnose einer diastolischen Dysfunktion nützlich sind, waren die Ergebnisse der gesamten Testdurchführung eher dürftig. Bei der systolischen Dysfunktion lag die diagnostische Genauigkeit weitaus höher. Es konnte gezeigt werden, dass die natriuretischen Peptide bei der Diagnose einer diastolischen Dysfunktion helfen können. Jedoch scheint die hohe Prävalenz der diastolischen Dysfunktion in der untersuchten Studiengruppe zur Erkennung der diastolischen Dysfunktion durch die Bestimmung der Plasmakonzentration der natriuretischen Peptide fragwürdig zu sein.

Weiterhin kann man die Hypothese aufstellen, dass durch die Kombination von zwei Markern die diagnostische Genauigkeit verbessert werden kann. Wenn die atriale Entleerung in den Ventrikel beeinträchtigt ist, sollte der atriale Wanddruck bei der diastolischen Dysfunktion überproportional erhöht sein. So wurde in dieser Arbeit angenommen, dass die Kombination von NT-proANP und NT-proBNP eine bessere diagnostische Genauigkeit im Vergleich zu einem einzelnen Marker hat. Dies war jedoch nicht der Fall. Daraus lässt sich schließen, dass die NT-proBNP und NT-proANP-Sekretion nicht so unterschiedlich reguliert wird, wie bisher angenommen wurde.

\subsection{Klinische Bedeutung}

Die gegenwärtige Definition der Herzinsuffizienz der American Heart Association benennt Stadien A-D und ersucht die Identifikation von Patienten mit strukturellen Herzerkrankungen (Stadium B) (Bonow et al. 2005).

Um die Wirkung der natriuretschen Peptide als Screening-Marker bei Patienten, die ein Risiko für eine Herzinsuffizienz haben, abzuschätzen, wurden die folgenden drei Annahmen gemacht:

1. Die Prävalenz dieser Erkrankung ist in der untersuchten Population hoch genug. Mit einer Prävalenz von 3\% der schweren diastolischen Dysfunktion und 3\% der systolischen Dysfunktion bei der untersuchten Bevölkerung ist diese Bedingung erfüllt. 
2. Eine Therapie für diese Patienten in einem asymptomatischen Stadium der Erkrankung ist vorgesehen. Es hat sich gezeigt, dass dieses für die systolische Dysfunktion zutrifft, da die ACE-Hemmer die Progression der Herzinsuffizienz reduziert. Für die schwere diastolische Dysfunktion sind vergleichbare pharmakodynamische Effekte noch nicht untersucht (SOLVD Investigators 1991; SOLVD Investigators 1992; Yusuf et al. 1992).

3. Es existiert ein diagnostischer Test mit einer hohen Sensitivität und Spezifität. Ein Screening-Test sollte eine hohe negative Vorhersage-Fähigkeit haben, so dass ein Testergebnis unter dem „cut-off” Punkt bei Patienten ohne Erkrankung am wahrscheinlichsten ist. Das aus den Ergebnissen der Studie neu entwickelte Score-System besitzt eine gute diagnostische Genauigkeit, insbesondere für die systolische und schwere diastolische Dysfunktion.

Folglich ist eine wichtige Erkenntnis dieser Arbeit, dass die Kombination von spezifischen klinischen Informationen und die Bestimmung der natriuretischen Peptide die diagnostische Genauigkeit gegenüber einer alleinigen Bestimmung der Plasmaspiegel natriuretischer Peptide verbessert.

NT-proBNP ist im direkten Vergleich zu NT-proANP und BNP der bessere Marker zur Aufdeckung einer linksventrikulären diastolischen und systolischen Dysfunktion bei Patienten mit vermuteter kardiologischer Erkrankung. Diese Feststellung lässt darauf schließen, dass in erster Linie die NT-proBNP-Plasmakonzentration ein wertvolles diagnostisches Werkzeug zur Feststellung einer sich verändernden linksventrikulären Funktion sowie Struktur bei Patienten mit dem Risiko für eine Herzerkrankung sein könnte.

Vor allem bei Patienten mit dem Risiko für die Entwicklung einer Herzinsuffizienz scheint die alleinige Bestimmung der Plasmapiegel natriuretischer Peptide nicht zur Diagnosestellung einer diastolischen Dysfunktion ausreichend zu sein. Das NT-proBNP ist vielmehr als ein Marker der neurohumoralen Aktivierung sowie eine Ergänzung zu klinischen und echokardiographischen Parametern in der Diagnostik einer symptomatischen diastolischen oder systolischen Herzinsuffizienz zu sehen. 


\subsection{Einschränkungen bei der Beurteilung der Ergebnisse dieser Untersuchung}

Mehrere Einschränkungen sollten bei der Interpretation der Ergebnisse bedacht werden.

Obgleich eine allgemeine Definition für die diastolische Dysfunktion gewählt wurde und signifikante Erhöhungen der natriuretischen Peptide bei Patienten mit diastolischer und systolischer Dysfunktion gefunden wurden, ist die Definition der diastolischen Dysfunktion Gegenstand von Diskussionen.

Bisher gab es keinen allgemein akzeptierten Algorithmus für die Diagnose und das Staging der diastolischen Dysfunktion (Redfield 2002; Bursi et al. 2006).

In einer Arbeit von Paulus et al. wurden erstmals Kriterien für die Diagnose, beziehungsweise Ausschlussdiagnose, einer diastolischen Dysfunktion festgelegt (Paulus et al. 2007).

Obwohl standardisierte echokardiographische Parameter angewendet wurden, kann nicht ausgeschlossen werden, dass andere Definitionen der diastolischen Dysfunktion, wenn diese mit den natriuretischen Peptiden bei präklinischer diastolischer Dysfunktion verglichen werden, zu abweichenden Ergebnissen führen. Überdies wurde eine linksventrikuläre Ejektionsfraktion $<50 \%$ für die Entdeckung einer linksventrikulären Dysfunktion gewählt. In anderen Studien wählten die Autoren eine linksventrikuläre Ejektionsfraktion von $<45 \%$ oder $<40 \%$ zur Aufdeckung einer systolischen Dysfunktion.

Das entwickelte Modell ist noch nicht bereit für den klinischen Gebrauch, da es in der gleichen Studienpopulation entwickelt und valiert wurde. Die Gültigkeit dieses Modells muss noch in einer unabhängigen Kohorte noch geprüft werden, bevor eine klinische Anwendung empfohlen werden kann.

Die natriuretischen Peptide können ein wertvolles Werkzeug zur Identifikation von Patienten mit dem Risiko einer Herzinsuffizienz sowie Marker für beanspruchtes Myokard sein. Hierbei sind sie mehr als eine Ergänzung zur Echokardiographie zur Identifikation von Patienten mit einem Risiko einer diastolischen oder systolischen Herzinsuffizienz zu sehen. Andererseits können keine relevanten Unterschiede beim Vergleich mit anderen Studien bezüglich des Einflusses der natriuretischen Peptide zur Vorhersage einer systolischen Dysfunktion gemacht werden (McDonagh et al. 2004; Groenning et al. 2004). 
Obwohl in der Studienpopulation das Geschlecht und die renale Funktion keinen Einfluss auf die diagnostische Durchführung dieser drei natriuretischen Peptide hatten, wiesen andere Studien unterschiedliche Ergebnisse auf (Bay et al. 2003; Luchner et al. 2002).

Es ist allerdings von Wichtigkeit, dass nahezu alle Patienten dieser Studie eine normale renale Funktion hatten. 


\section{$5 \quad$ Zusammenfassung}

Zusammenfassend kann gesagt werden, dass die Prävalenz einer präklinischen systolischen oder diastolischen Dysfunktion bei Patienten mit Risikofaktoren für die Entwicklung einer Herzinsuffizienz hoch ist und dass die Erkennung dieser Patienten von klinischer Relevanz ist. Die natriuretischen Peptide steigen signifikant mit Abnahme der Ejektionsfraktion sowie mit dem Anstieg der diastolischen Dysfunktion an. Allerdings scheint ihre Bedeutung zur Aufdeckung einer leichten oder moderaten diastolischen Dysfunktion begrenzt zu sein. Werden jedoch klinische Parameter mit der Plasmakonzentration der natriuretischen Peptide kombiniert, so verbessert dies die diagnostische Genauigkeit und reduziert die Anzahl der benötigten echokardiographischen Untersuchungen für die Identifikation von Patienten mit einer linksventrikulären systolischen oder diastolischen Dysfunktion. Solche Patienten, die ein hohes Risiko für eine diastolische Dysfunktion haben, können möglicherweise unter dem Gebrauch eines Screeningscores, welcher klinische und biochemische (hier NT-proBNP) Parameter vereinigt, am effektivsten erkannt werden. 


\section{$6 \quad$ Literaturverzeichnis}

Andersson B, Hall C (2000): N-terminal proatrial natriuretic peptide and prognosis in patients with heart failure and preserved systolic function. J Card Fail $\underline{6}, 208-213$

Armstrong PW, Moe GW (1994): Medical advances in the treatment of congestive heart failure. Circulation $\underline{88}, 2941-2952$

Aurigemma GP, Gaasch WH (2004): Diastolic heart failure. N Engl J Med 351, 1097-1105

Baessler A, Fischer M, Schunkert H (2003): Die chronische Herzinsuffizienz - ein oft vermeidbares Schicksal. Dtsch Med Wochenschr $\underline{128}$, 1489-1493

Bay M, Kirk V, Parner J, Hassager C, Nielsen H, Krogsgaard K, Trawinski J, Boesgaard S, Aldershvile J (2003): NT-proBNP: a new diagnostic screening tool to differentiate between patients with normal and reduced left ventricular systolic function. Heart $\underline{89}$, $150-154$

Berger R, Huelsman M, Stecker K, Bojic A, Moser P, Stanek B, Pacher R (2002): B-type natriuretic peptide predicts sudden death in patients with chronic heart failure. Circulation $\underline{105}, 2392-2397$

Bonow RO, Bennett S, Casey DE, Jr., Ganiats TG, Hlatky MA, Konstam MA, Lambrew CT, Normand SL, Pina IL, Radford MJ, Smith AL, Stevenson LW, Burke G, Eagle KA, Krumholz HM, Linderbaum J, Masoudi FA, Ritchie JL, Rumsfeld JS, Spertus JA (2005): ACC/AHA Clinical Performance Measures for Adults with Chronic Heart Failure: a report of the American College of Cardiology/American Heart Association Task Force on Performance Measures (Writing Committee to Develop Heart Failure Clinical Performance Measures): endorsed by the Heart Failure Society of America. Circulation $\underline{112}, 1853-87$

Bouvy ML, Heerdink ER, Leufkens HG, Hoes AW (2003): Predicting mortality in patients with heart failure: a pragmatic approach. Heart $\underline{89}$, 605-609

Bursi F, Weston SA, Redfield MM, Jacobsen SJ, Pakhomov S, Nkomo VT, Meverden RA, Roger VL (2006): Systolic and diastolic heart failure in the community. JAMA $\underline{296}$, 2209-2116

Cheitlin MD, Armstrong WF, Aurigemma GP, Beller GA, Bierman FZ, Davis JL, Douglas PS, Faxon DP, Gillam LD, Kimball TR, Kussmaul WG, Pearlman AS, Philbrick JT, Rakowski H, Thys DM, Antman EM, Smith SC, Jr., Alpert JS, Gregoratos G, Anderson JL, Hiratzka LF, Hunt SA, Fuster V, Jacobs AK, Gibbons RJ, Russell RO (2003): ACC/AHA/ASE 2003 Guideline Update for the Clinical Application of 
Echocardiography: summary article. A report of the American College of Cardiology/American Heart Association Task Force on Practice Guidelines (ACC/AHA/ASE Committee to Update the 1997 Guidelines for the Clinical Application of Echocardiography). Circulation 108, 1146-1162

Choy AM, Darbar D, Lang CC, Pringle TH, McNeill GP, Kennedy NS, Struthers AD (1994): Detection of left ventricular dysfunction after acute myocardial infarction: comparison of clinical, echocardiographic, and neurohormonal methods. Br Heart J $\underline{72}, 16-22$

CIBIS-II Investigators (1999): The Cardiac Insufficiency Bisoprolol Study II (CIBIS-II): a randomised trail. Lancet $\underline{353}, 9-13$

Cicoira M, Zanolla L, Rossi A, Golia G, Franceschini L, Brighetti G, Marino P, Zardini P (2002): Long-term, dose-dependent effects of spironolactone on left ventricular function and exercise tolerance in patients with chronic heart failure. J Am Coll Cardiol 40, 304-310

Cleland JG, Erhardt L, Murry G, Hall AS, Ball SG, On behalf of the AIRE Study Investigators (1997): Effect of ramipril on morbidity an mode of death among survivors of acute myocardial infarction with clinical evidence of heart failure. Eur Heart J $\underline{18}, 41-51$

Cleland JG, Schwedberg K, Follath F, Komajda N, Cohen-Solal A, Aguilar JC, Dietz R, Gavazzi A, Hobbs R, Korewicki J, Madeira HC, Moiseyev VS, Preda I, van Gilst WH, Widimsky J, Freemantle N, Eastaugh J, Mason J (2003): The EuroHeart Failure survey programme - a survey on the quality of care among patients with heart failure in Europe. Part 1: patient characteristics and diagnosis. Eur Heart J 24 4, 442-463

Cohn JN, Ferrari R, Sharpe N (2000): Cardiac remodeling - concepts and clinical implications: a consensus paper from an international forum on cardiac remodeling. Behalf of an International Forum on Cardiac Remodeling. J Am Coll Cardiol 35, 56982

CONSENSUS Trail Study Group (1987): Effects of enalapril on mortality in severe congestic heart failure: Results of the Cooperativ North Scandinavian Enalapril Survival Study (CONSENSUS). N Engl J Med $\underline{316}, 1429-1435$

Dahlstrom U (2004): Can natriuretic peptides be used for the diagnosis of diastolic heart failure? Eur J Heart Fail 므, 281-287

Dao Q, Krishnaswamy P, Kazanegra R, Harrison A, Amirnovin R, Lenert L, Clopton P, Alberto J, Hlavin P, Maisel AS (2001): Utility of B-Type Natriuretic Peptide in the 
Diagnosis of Congestive Heart Failure in an Urgent-Care Setting. J Am Coll Cardiol $\underline{37}, 379-385$

Davis M, Espiner E, Richards G, Billings J, Town I, Neill A, Drennan C, Richards M, Turner J, Yandle T (1994): Plasma brain natriuretic peptide in assessment of acute dyspnoea. Lancet $\underline{343}, 440-444$

De Bold AJ, Borenstein HB, Veress AT, Sonnenberg H (1981): A rapid and potent natriuretic response to intravenous injection of atrial myocardial extracts in rats. Life Sci $\underline{28}, 89$ 94

Dickstein K, Cohen-Solal A, Filippatos G, McMurray JJV, Ponikowski P, Poole-Wilson PA, Srömberg A, van Veldhuisen DJ, Atar D, Hoes AW, Keren A, Mebazaa A, Nieminen M, Priori SG, Swedberg K (2008): ECS Guidelines for the diagnosis and treatment of acute and chronic heart failure. Eur Heart J $\underline{29}$, 2388-2442

Digitalis Investigation Group (1997): The effect of digoxin on mortality and morbidity in patients with heart failure. N Engl J Med $\underline{336}, 525-533$

Erbel R, Neumann T, Zeidan Z, Bartel T, Buck T (2002): Echokardiographische Diagnostik der diastolischen Herzinsuffizienz. Herz 27, 99-106

Erdmann E: Herzinsuffizienz. Ursachen, Pathophysiologie und Therapie. 3. Auflage; Wissenschaftliche Verlagsgesellschaft, Stuttgart 2003.

European Study Group on Diastolic Heart Failure (1998): How to diagnose diastolic heart failure. Eur Heart J $\underline{19}$, 990-1003

Gaasch WH, Zile MR (2004): Left ventricular diastolic Dysfunction and diastolic heart failure. Annu Rec Med 55, 373-394

Gandhi SK, Powers JC, Nomeir AM, Fowle K, Kitzman DW, Rankin KM, Little WC (2001): The pathogenesis of acute pulmonary edema associated with hypertension. N Engl $\mathbf{J}$ Med 344, 17-22

Garcia MJ, Thomas JD, Klein Al (1998): New Doppler echocardiographic applications for the study of diastolic dysfunction. J Am Coll Cardiol $\underline{32}$, 865-875

Granger CB, McMurray JJ, Yusuf S, Held P, Michelson EL, Olofsson B, Östergren J, Pfeffer MA, Swedberg K (2003): Effects of candesartan in patients with chronic heart failure and reduced left-ventricular systolic function intolerant to angiotensin-convertingenzyme inhibitors: the CHARM-Alternative trial. Lancet $\underline{362}$, 772-776 
Groenning BA, Raymond I, Hildebrandt PR, Nilsson JC, Baumann M, Pedersen F (2004): Diagnostic and prognostic evaluation of left ventricular systolic heart failure by plasma $\mathrm{N}$-terminal pro-brain natriuretic peptide concentrations in a large sample of the general population. Heart $\underline{90}$, 297-303

Gustafsson F, Torp-Pedersen C, Brendorp B, Seibaek M, Burchardt H, Kober L (2003): Longterm survival in patients hospitalized with congestive heart failure: relation to preserved and reduced left ventricular systolic function. Eur Heart J $\underline{24}, 863-870$

Hall C, Ihlen H, Bonarjee V, Dickstein K, Kjekshus J (2003): N-terminal proatrial natriuretic peptide in primary care: relation to echocardiographic indices of cardiac function in mild to moderate cardiac disease. Int J Cardiol $\underline{89}$, 197-205

Hawkins DM, Basak SC, Mills D (2003): Assessing model fit by cross-validation. J Chem Inf Comput Sci $\underline{43}, 579-86$

Hjalmarson A, Goldstein S, Fagerberg B, Wedel H, Waagstein F, Kjekshus J, Wikstrand J, El Allaf D, Vitovec J, Aldershvile J, Halinen M, Dietz R, Neuhaus KL, Janosi A, Thorgeirsson G, Dunselman PH, Gullestad L, Kuch J, Herlitz J, Rickenbacher P, Ball S, Gottlieb S, Deedwania P (2000): Effects of controlled-release metoprolol on total mortality, hospitalizations, and well-being in patients with heart failure: the Metoprolol CR/XL Randomized Intervention Trial in congestive heart failure (MERIT-HF). MERIT-HF Study Group. JAMA $\underline{283}, 1295-302$

Hobbs FD, Davis RC, Roalfe AK, Hare R, Davies MK (2004): Reliability of N-terminal proBNP assay in diagnosis of left ventricular systolic dysfunction within representative and high risk populations. Heart $\underline{90}, 866-870$

Holmes SJ, Espiner EA, Richards AM, Yandle TG, Frampton C (1993): Renal, endocrine and haemodynamic effects of human brain natriuretic peptide in normal man. J Clin Endocrinol Metab $\underline{76}, 91-96$

Hülsmann M, Berger R, Sturm B, Bojic A, Woloszczuk W, Bergler-Klein J, Pacher R (2002): Prediction of outcome by neurohumoral activation, the six-minute walk test and the Minnesota Living with Heart Failure Questionnaire in an outpatient cohort with congestive heart failure. Eur Heart J $\underline{23}, 886-891$

Hunt HA, Baker DW, Chin MH, Cinquegrani MP, Feldmanmd AM, Francis GS, Ganiats TG, Goldstein S, Gregoratos G, Jessup ML, Noble RJ, Packer M, Silver MA, Stevenson LW, Gibbons RJ, Antman EM, Alpert JS, Faxon DP, Fuster V, Jacobs AK, Hiratzka LF, Russell RO, Smith SC, Jr (2001) ACC/AHA Guidelines for the Evaluation and Management of Chronic Heart Failure in the Adult. Circulation 104, 2996-3007 
Johnston B, Seshia SS (1992): Discriminant analysis when all variables are ordered. Stat Med $\underline{11}, 1023-32$

Kelly R, Struthers A (2001): Are natriuretic peptides clinically useful as markers of heart failure? Ann Clin Biochem $\underline{38}$, 94-102

Kober L, Torp-Pedersen C, Carlsen JE, Bagger H, Eliasen P, Lynborg K, Videbaek J, Cole DS, Auclert L, Pauly NC, Aliot E, Persson S, Camm AJ (1995): A clinical trail of the angiotensin-converting-enzyme inhibitor trandolapril in patients with left ventricular dysfunction after myocardial infarction. Trandolapril Cardiac Evaluation (TRACE) Study Group. N Engl J Med $\underline{333}$, 1670-1676

Krishnaswamy P, Lubien E, Clopton P, Koon J, Kazanegra R, Wanner E, Gardetto N, Garcia A, DeMaria A, Maisel AS (2001): Utility of B-natriuretic peptide levels in identifying patients with left ventricular systolic or diastolic dysfunction. Am J Med 111, 274-279

Krum H, Roecker EB, Mohacsi P, Rouleau JL, Tendera M, Coats AJ, Katus HA, Fowler MB, Packer M (2003): Effects of initiating carvedilol in patients with severe chronic heart failure: Results from the COPERNICUS Study. JAMA $\underline{289}$, 712-718

Lee WC, Chavez YE, Baker T, Luce BR (2004): Economic burden of heart failure: a summary of recent literature. Heart Lung $\underline{33}, 362-371$

Lerman A, Gibbons RJ, Rodeheffer RJ, Bailey KR, McKinley LJ, Heublein DM, Burnett JC, $\mathrm{Jr}$ (1993): Circulating N-terminal atrial natriuretic peptide as a marker for symptomless left-ventricular dysfunction. Lancet $\underline{341}, 1105-1109$

Lubien E, DeMaria A, Krishnaswamy P, Clopton P, Koon J, Kazanegra R, Gardetto N, Wanner E, Maisel AS (2002): Utility of B-natriuretic peptide in detecting diastolic dysfunction: comparison with Doppler velocity recordings. Circulation $\underline{105}, 595-601$

Luchner A, Hengstenberg C, Löwel H, Trawinski J, Baumann M, Riegger GA, Schunkert H, Holmer S (2002): N-Terminal Pro-Brain Natriuretic Peptide After Myocardial Infarction: A Marker Of Cardio-Renal Function. Hypertension 39, 99-104

McDonagh TA, Robb SD, Murdoch DR, Morton JJ, Ford I, Morrison CE, Tunstall-Pedoe H, McMurray JJ, Dargie HJ (1998): Biochemical detection of left-ventricular systolic dysfunction. Lancet $\underline{351}, 9-13$

McDonagh TA, Holmer S, Raymond I, Luchner A, Hildebrant P, Dargie HJ (2004): NTproBNP and the diagnosis of heart failure: a pooled analysis of three European epidemiological studies. Eur J Heart Fail ㅁ, 269-273

McKee P, Castelli W, McNamara P, Kannel W (1971): The Natural History of Congestive Heart Failure: The Framingham Study. N Engl J Med 285, 1441-1446. 
MERIT-HF Study Group (1999): Effect of metoprolol CR/XL in chronic heart failure: Metoprolol CR/XL Randomised Intervention Trial in Congestive Heart Failure (MERIT-HF). Lancet $\underline{353}$, 2001-2007

Morrison LK, Harrison A, Krishnaswamy P, Kazanegra R, Clopton P, Maisel A (2002): Utility of a rapid B-natriuretic peptide assay in differentiating congestive heart failure from lung disease in patients presenting with dyspnea. J Am Coll Cardiol 39, 202-209

Motwani JG, McAlpine H, Kennedy N, Struthers AD (1993): Plasma brain natriuretic peptide as an indicator for angiotensin-converting-enzyme inhibition after myocardial infarction. Lancet $\underline{341}, 1109-1113$

Mueller C, Scholer A, Laule-Kilian K, Martina B, Schindler C, Buser P, Pfisterer M, Perruchoud AP (2004): Use of B-type natriuretic peptide in the evaluation and management of acute dyspnea. N Engl J Med $\underline{350}, 647-654$

Mueller T, Gegenhuber A, Poelz W, Haltmayer M (2005): Diagnostic accuracy of B type natriuretic peptide and amino terminal proBNP in the emergency diagnosis of heart failure. Heart 91, 606-612

Nagueh SF (2004): Tissue Doppler imaging for the pre-clinical diagnosis of cardiomyopathy. Eur Heart J 25, 1865-1866

Nagueh SF, Rao L, Soto J, Middleton KJ, Khoury DS (2004): Haemodynamic insights into the effects of ischaemia and cycle length on tissue Doppler-derived mitral annulus diastolic velocities. Clin Sci (Lond) $\underline{106}, 147-154$

Nakagawa O, Ogawa Y, Itoh H, Suga S, Komatsu Y, Kishimoto I, Nishino K, Yoshimasa T, Nakao K (1995): Rapid transcriptional activation and early mRNA turnover of brain natriuretic peptide in cardiocyte hypertrophy. Evidence for brain natriuretic peptide as an "emergency" cardiac hormone against ventricular overload. J Clin Invest $\underline{96}, 1280$ 1287

Nakao K, Ogawa Y, Suga S, Imura H (1992): Molecular biology and biochemistry of the natriuretic peptide system I: natriuretic peptides. J Hypertens 10, 907-912

Ofman JJ, Badamgarav E, Henning JM, Knight K, Gano AD, Jr., Levan RK, Gur-Arie S, Richards MS, Hasselblad V, Weingarten SR (2004): Does disease management improve clinical and economic outcomes in patients with chronic diseases? A systematic review. Am J Med 117, 182-192

Olsen MH, Wachtell K, Tuxen C, Fossum E, Bang LE, Hall C, Ibsen H, Rokkedal J, Devereux RB, Hildebrandt P (2004): N-terminal pro-brain natriuretic peptide predicts 
cardiovascular events in patients with hypertension and left ventricular hypertrophy: a LIFE study. J Hypertens 22, 1597-1604

Owen A (2006): Life expectancy of elderly and very elderly patients with chronic heart failure. Am Heart J $\underline{151}, 1322$

Packer M, Bristow MR, Cohn JN, Colucci WS, Fowler MB, Gilbert EM, Shusterman NH (1996): The effect of carvedilol on morbidity and mortality in patients with chronic heart failure. U.S. Carvedilol Heart Failure Study Group. N Engl J Med 334, 13491355

Paulus WJ, Tschöpe C, Sanderson JE, Rusconi C, Flachskampf FA, Rademakers FE, Marino P, Smiseth OA, De Keulenaer G, Leite-Moreira AF, Borbely A, Edes I, Handoko ML, Heymans S, Pezzali N, Pieske B, Dickstein K, Fraser AG, Brutsaert DL (2007): How to diagnose diastolic heart failure: a consensus statement on the diagnosis of heart failure with normal left ventricular ejection fraction by the Heart Failure and Echocardiography Associations of the European Society of Cardiology. Eur Heart J $\underline{28}, 2539-2550$

Pfeffer MA, Braunwald E, Moye LA, Basta L, Brown EJ jr., Cuddy TE, Davis BR, Geltman EM, Goldman S, Flaker GC, Klein M, Lamas GA, Packer M, Rouleau J, Rouleau JL, Rutherford J, Wertheimer JH, Hawkins CM (1992): Effect of captopril on mortality and morbidity in patients with left ventricular dysfunction after myocardial infarction. Results of the survival an ventricular enlargement trail. The SAVE Investigators: N Engl J Med 327, 669-677

Poerner TC, Goebel B, Unglaub P, Sueselbeck T, Strotmann JM, Pfleger S, Borggrefe M, Haase KK (2003): Detection of a pseudonormal mitral inflow pattern: an echocardiographic and tissue Doppler study. Echocardiography 20, 345-356

Pozzoli M, Traversi E, Cloffi G, Stenner R, Sanarico M, Tavazzi L (1997): Loading manipulations improve the prognosis value of Doppler evaluation of mitral flow in patients with chronic heart failure. Circulation $\underline{95}$, 1222-1230

Quinones MA, Otto CM, Stoddard M, Waggoner A, Zoghbi WA (2002): Recommendations for quantification of Doppler echocardiography: a report from the Doppler Quantification Task Force of the Nomenclature and Standards Committee of the American Society of Echocardiography. J Am Soc Echocardiogr 15, 167-84

Ramires FJ, Mansur A, Coelho O, Maranhao M, Gruppi CJ, Mady C, Ramires JA (2000): Effect of Spironolactone on ventricular arrhythmias in congestive heart failure 
secondary to idiopathic dilated or to ischemic cardiomyopathy. Am J Cardiol $\underline{85}$, $1207-1211$

Redfield MM (2002): Heart failure - an epidemic of uncertain proportions. N Engl J Med $\underline{347}, 1442-1444$

Redfield MM (2004): Understanding “diastolic” heart failure. N Engl J Med 플, 1930-1931

Redfield MM, Jacobsen SJ, Burnett JC Jr., Mahoney DW, Bailey KR, Rodeheffer RJ (2003): Burden of systolic and diastolic ventricular dysfunction in the community: Appreciating the scope of the heart failure epidemic. JAMA $\underline{289}$, 194-202

Richards AM (2004): The natriuretic peptides in heart failure. Basic Res Cardiol 99, 94-100

Roche Diagnostics. Pro Brain Natriuretic Peptide Packungsbeilage. Mannheim: Roche Diagnostics GmbH, 2002.

Rossi A, Cicoira M, Florea VG, Golia G, Florea ND, Khan AA, Murray ST, Nguyen JT, O'Callaghan P, Anand IS, Coats A, Zardini P, Vassanelli C, Henein M (2006): Chronic heart failure with preserved left ventricular ejection fraction: diagnostic and prognostic value of left atrial size. Int J Cardiol $\underline{110}, 386-392$

Senni M, Redfield MM (2001): Heart failure with preserved systolic function. A different natural history? J Am Coll Cardiol $\underline{38}, 1277-1282$

SOLVD Investigators (1991): Effect of enalapril on survival in patients with reduced left ventricular ejection fractions and congestive heart failure. N Engl J Med 325, 293-302

SOLVD Investigators (1992): Effect of enalapril on mortality and the development of heart failure in asymptomatic patients with reduced left ventricular ejection fractions. $\mathrm{N}$ Engl J Med 327, 685-691

Stein BC, Levin RI (1998): Natriuretic peptides: physiology, therapeutic potential, and risk stratification in ischemic heart disease. Am Heart J 135, 914-923

Sudoh T, Kangawa K, Minamino N, Matsuo H (1988): A new natriuretic peptide in porcine brain. Nature $\underline{332}, 78-81$

Sudoh T, Minamino N, Kangawa K, Matsuo H (1990): C-type natriuretic peptide (CNP): a new member of natriuretic peptide family identified in porcine brain. Biochem Biophys Res Commun $\underline{168}, 863-870$

Swedberg K, Cleland J, Dargie H, Drexler H, Follath F, Komajda M, Tavazzi L, Smiseth OA, Gavazzi A, Haverich A, Hoes A, Jaarsma T, Korewicki J, Levy S, Linde C, LopezSendon JL, Nieminen MS, Pierard L and Remme WJ (2005): Guidelines for the diagnosis and treatment of chronic heart failure: executive summary (update 2005): 
The task force for the diagnosis and treatment of chronic heart failure of the European Society of Cardiology. Eur Heart J 26, 1115-1140

Tamura N, Ogawa Y, Yasoda A, Itoh H, Saito Y, Nakao K (1996): Two cardiac natriuretic peptide genes (atrial natriuretic peptide and brain natriuretic peptide) are organized in tandem in mouse and human genomes. J Mol Cell Cardiol 28, 1811-1815

Valli N, Gobinet A, Bordenave L (1999): Review of 10 years of the clinical use of brain natriuretic peptide in cardiology. J Lab Clin Med $\underline{134}$, 437-444

Vasan RS, Levy D (2000): Defining diastolic heart failure. Circulation 101, 2118-2121

Vasan RS, Benjamin EJ, Levy D (1995): Prevalence, clinical features and prognosis of diastolic heart failure: an epidemiologic perspective. J Am Coll Cardiol 26, 1565-1574

Voelker W (2004): A structured report data set for documentation of echocardiographic studies - Update 2004. Z Kardiol 93, 987-1004

Wallén T, Landahl S, Hedner T, Saito Y, Masuda I, Nakao K (1997): Brain natriuretic peptide in an elderly population. $\mathrm{J}$ Intern Med 242, 307-311

WHO. Physician Guidelines (for GPs) designed to be translated and distributed worldwide to primary care physicians. 1995.

Wilkins MR, Redondo J, Brown LA (1997): The natriuretic-peptide family. Lancet $\underline{349}$, $1307-1310$

Wollert KC, Drexler H (1998): Akute Herzinsuffizienz. Internist 39, 459-466

Yamada Y, Goto J, Yokota M (1997): Brain Natriuretic Peptide Is a Sensitive Indicator of Impaired Left-Ventricular Function in Elderly Patients with Cardiovascular Disease. Cardiology $\underline{88}, 401-407$

Youden W (1950): Index for rating diagnostic tests. Cancer 32-35

Yusuf S, Pepine CJ, Garces C, Pouleur H, Salem D, Kostis J, Benedict C, Rousseau M, Bourassa M, Pitt B (1992): Effect of enalapril on myocardial infarction and unstable angina in patients with low ejection fractions. Lancet $\underline{340}, 1173-1178$

Zile MR, Brutsaert DL (2002): New concepts in diastolic dysfunction and diastolic heart failure. Part 1: diagnosis, prognosis, and measurements of diastolic function. Circulation $\underline{105}, 1387-1393$ 


\section{Danksagung}

Mein ganz besonderer Dank gilt meinem Doktorvater Prof. Dr. med. B Pieske für die Bereitstellung dieses Themas. Er ermöglichte mir selbstständiges Arbeiten während der Zeit der klinischen Studie und stand mir motivierend und anregend zur Seite.

Besonderer Dank gilt auch der gesamten Arbeitsgruppe, die durch ein hohes Maß an Flexibilität und Teamarbeit für ein sehr angenehmes Arbeitsklima, an manch anstrengenden Untersuchungstagen in Flur 10 der Kardiologie, sorgte.

Herausheben möchte ich Dr. med. Claus Luers und Dr. med. Sibylle Kleta, sowie Dr. med. Rolf Wachter, die alle in den unterschiedlichen Phasen dieser Studie mir motivierend und unterstützend zur Seite standen. 


\section{Lebenslauf}

Am 11. Dezember 1974 wurde, ich Marc Uhlir, als erstes Kind von Gudrun und Werner Uhlir in Kassel geboren.

Von 1981 bis 1985 besuchte ich die Langenberg Grundschule in Baunatal. Im Jahr 1985 wechselte ich auf die Erich-Kästner-Gesamtschule in Baunatal, die ich 1991 verließ, um meine Fachhochschulreife 1993 an der Paul-Julius-von-Reuter-Schule in Kassel abzulegen.

1993 begann ich ein Bauingenieurstudium an der GHK Kassel, welches ich 1994 abbrach, um meine Zivildienst abzuleisten.

In den Jahren 1994 und 1995 leistete ich meinen Zivildienst beim Arbeiter-Samariter-Bund in Lohfelden ab. Hier konnte ich den Abschluss zum Rettungssanitäter erlangen.

1996 begann ich mit der Ausbildung zum Rettungsassistenten, die ich im gleichen Jahr erfolgreich abschließen konnte.

Von 1996 bis 1998 arbeitete ich hauptberuflich beim Arbeiter-Samariter-Bund in Lohfelden als Rettungsassistent.

1998 entschloss ich mich, meine Allgemeine Hochschulreife auf dem zweiten Bildungsweg an dem Hessenkolleg Kassel zu beginnen, welche ich dann 2001 erfolgreich ablegte.

Vom Wintersemester 2001/2002 bis einschließlich zum Wintersemester 2007/ 2008 studierte ich an der Georg-August-Universität Göttingen Humanmedizin. Im Frühsommer 2004 begann ich nach erfolgreich abgelegtem Physikum meine Dissertationsarbeit im Zentrum Innere Medizin, Abteilung Kardiologie und Pneumologie (Professor Dr. med. G. Hasenfuß), Herzzentrum, bei Professor Dr. med. B. Pieske. Mein Staatsexamen legte ich im Herbst/Winter 2007 ab.

Meine Famulaturen absolvierte ich unter anderem in der Allgemeinchirurgie, der Kardiologie, der Unfallchirurgie sowie der Plastischen Chirurgie. In meinem Praktischen Jahr absolvierte ich das chirurgische Tertial in den Kliniken Herzberg und Osterode GmbH, das Tertial der 
Inneren Medizin an der Universitätsklinik Göttingen und mein Wahlfach Gynäkologie in den Asklepios Harzkliniken Goslar.

1995 bis 1996 war ich als Rettungssanitäter sowie ab 1998 bis 2008 als Rettungsassistent beim Arbeiter-Samariter-Bund Lohfelden teilzeitbeschäftigt.

Seit dem 1. Januar 2008 arbeite ich als Assistenzarzt in der unfallchirurgischen Abteilung der Kliniken Herzberg und Osterode GmbH. 